\title{
Functional and Phenotypic Differences of Pure Populations of Stem Cell-Derived Astrocytes and Neuronal Precursor Cells
}

\author{
Susanne Kleiderman, ${ }^{1}$ João V. Sá, ${ }^{2,3}$ Ana P. Teixeira, ${ }^{2,3}$ Catarina Brito, ${ }^{2,3}$ Simon Gutbier, ${ }^{1}$ \\ Lars G. Evje, ${ }^{4}$ Mussie G. Hadera, ${ }^{5}$ Enrico Glaab, ${ }^{6}$ Margit Henry, ${ }^{7}$ Agapios Sachinidis, ${ }^{7}$ \\ Paula M. Alves, ${ }^{2,3}$ Ursula Sonnewald, ${ }^{8,9}$ and Marcel Leist ${ }^{1}$
}

\begin{abstract}
Availability of homogeneous astrocyte populations would facilitate research concerning cell plasticity (metabolic and transcrip tional adaptations; innate immune responses) and cell cycle reactivation. Current protocols to prepare astrocyte cultures differ in their final content of immature precursor cells, preactivated cells or entirely different cell types. A new method taking care of all these issues would improve research on astrocyte functions. We found here that the exposure of a defined population of pluripotent stem cell derived neural stem cells (NSC) to BMP4 results in pure, nonproliferating astrocyte cultures within $2448 \mathrm{~h}$. These murine astrocytes generated from embryonic stem cells (mAGES) expressed the positive markers GFAP, aqua porin 4 and GLT 1, supported neuronal function, and acquired innate immune functions such as the response to tumor necro sis factor and interleukin 1. The protocol was applicable to several normal or disease prone pluripotent cell lines, and the corresponding mAGES all exited the cell cycle and lost most of their nestin expression, in contrast to astrocytes generated by serum addition or obtained as primary cultures. Comparative gene expression analysis of mAGES and NSC allowed quantifi cation of differences between the two cell types and a definition of an improved marker set to define astrocytes. Inclusion of several published data sets in this transcriptome comparison revealed the similarity of mAGES with cortical astrocytes in vivo. Metabolic analysis of homogeneous NSC and astrocyte populations revealed distinct neurochemical features: both cell types synthesized glutamine and citrate, but only mature astrocytes released these metabolites. Thus, the homogeneous cultures allowed an improved definition of NSC and astrocyte features.
\end{abstract}

Key words: astrocytes, neural stem cells, differentiation, metabolic flux, transcriptome

\section{Introduction}

T he definition of astrocyte functions and developmental potential, in particular in relation to neural stem cells, is still a dynamic area of research (Bayraktar et al., 2015; Gotz et al., 2015; Robel et al., 2011). Astrocytes and neural stem cells (NSC) share several phenotypic and functional features (Doetsch et al., 1999; Kriegstein and Alvarez Buylla, 2009; Levitt and Rakic, 1980; Seri et al., 2001). Moreover, some types of NSC (radial glia or astrocytes from the subventricu lar zone) have been categorized as members of the 
heterogeneous group of astrocytes, due to their expression of the glial fibrillary acidic protein (GFAP), the most fre quently used astrocyte marker (Eng et al., 2000; Ihrie and Alvarez Buylla, 2008; Steindler and Laywell, 2003). Under pathophysiological conditions, astrocyte behavior shows high plasticity (Parpura et al., 2012) and reversion to an NSC like precursor state has been observed (Gotz et al., 2015; Sirko et al., 2013).

Astrocytes play a pivotal role in brain metabolism (Amaral et al., 2011; McKenna et al., 2012; Waagepetersen et al., 2009) and in linking neurons and other brain cells to blood supply (Kacem et al., 1998). Beside their role in meta bolic homeostasis, astrocytes efficiently take up neurotrans mitters like glutamate (Zhou and Danbolt, 2013), and thus modulate synaptic function (Perea et al., 2009). In this con text, glial glutamine synthetase (Glul) catalyzes the condensa tion of ammonia to imported glutamate to produce glutamine, which is then released, and taken up by neurons to produce glutamate again (Daikhin and Yudkoff, 2000). This dynamic recycling mechanism of glutamate, considered essential to prevent neuronal excitotoxicity (Delaney et al., 1996), is thought to be astrocyte specific. However, NSC also express the glutamate aspartate transporter GLAST (Liu et al., 2006; Ullensvang et al., 1997) and glutamine synthe tase (Hernández et al., 1999; Monzon Mayor et al., 1990; Suarez et al., 1997) and their potential role in glutamate metabolism therefore deserves attention.

For the study of astrocyte metabolism and function, pri mary monolayer cultures have become the dominating model system. However, contamination with other cell types such as microglia (Saura, 2007), requires stringent controls and the contribution of immature cells with high levels of nestin expression to standard primary cultures has often been neglected (Hansson, 1986; Sergent Tanguy et al., 2006; Stahl berg et al., 2011). An alternative approach to obtain astro cytes is to use neurospheres from embryonic stem cells (ESC) (Kuegler et al., 2012) or brain (Crocker et al., 2008) as start ing material for astrocytogenesis. The resulting astrocyte population is free of microglia, but it may still contain nestin positive precursors and various proliferating cell types. The same applies to the generation of human astrocytes from pluripotent stem cells. Several corresponding protocols gener ate GFAP positive cells (Krencik et al., 2011; Roybon et al., 2013; Shaltouki et al., 2013), but they all still contain sizable subpopulations of immature or contaminating cells that might spoil results of gene expression analysis, identification of metabolic pathways, or cell fate examinations.

Compared with astrocytes, hardly any data is available on metabolism or inflammatory reactions of their precursor cells and of NSC. A major reason for this paucity of information may be the limited access to suitable experimental systems. Iso lation of defined and sufficiently large populations of primary cells is difficult, and NSC amplified in vitro in the form of neurospheres often comprise heterogeneous subpopulations that are challenging to handle for biochemical studies.

A new option to study NSC was provided by the discov ery that such cells may be cultured and propagated as highly homogeneous monolayer cultures (Conti et al., 2005). This seminal work mainly described the use of the cells to study neurogenesis, but it was also shown that this NSC cell popula tion differentiated to GFAP positive cells within $48 \mathrm{~h}$ of expo sure to serum (Conti et al., 2005). These data suggested an attractive way of producing astrocytes (Schneider, 2014; Schnei der and d'Adda di Fagagna, 2012; Sparmann et al., 2013), but more characterization of the resultant cells is necessary, and the original protocol requires adaptations and further specifications before pure cultures of astrocytes can be obtained reproducibly.

Since there is a great, yet largely unrecognized, potential in the astrocyte generation from NSC, we set out to (i) define the critical steps of the procedure, (ii) to characterize the result ing cells, and (iii) to demonstrate the usefulness of a protocol adapted from Conti et al. (2005) for generating NSC and astro cyte populations. This allowed us for the first time a direct com parison of NSC and homogeneous, nonproliferating astrocytes concerning differentiation response, neuronal support, immune activation, differentially expressed genes, and metabolic features with clear differences identified between the two cell types.

\section{Materials and Methods}

\section{Maintenance of Murine Embryonic Stem Cells}

The murine embryonic stem cell (mESC) lines CGR8.0, E14, BTBR T+ Itpr3tf/J PB60.6 (The Jackson Laboratory, 002282C01), DO335.45 (Diversity Outbred strain, Jax number 009376), and O9 iPS (Wernig et al., 2007) were maintained in Glasgow Minimum Essential Medium (GMEM) containing high glucose (4.5 g/L), 10\% fetal bovine serum (FBS), $2 \mathrm{mM}$ Glutamax, $2 \mathrm{mM}$ sodium pyruvate, $2 \mathrm{mM}$ nonessential amino acids, and $50 \mu \mathrm{M} \beta$ mercaptoethanol (materials are listed in the Supp. Info.). Medium was changed every day with freshly added $1,000 \mathrm{U} / \mathrm{mL}$ leukemia inhibitory factor (LIF). Cells were passaged every other day with $0.05 \%$ trypsin and replated on Nunclon ${ }^{\mathrm{TM}}$ Delta flasks (Thermo Scientific) coated for $1 \mathrm{~h}$ with $0.1 \%$ gelatin dissolved in water.

\section{Differentiation of Neural Stem Cells From mESC}

Cultures of mESC were used when they reached $80 \%$ confluency. Cells were harvested with $0.05 \%$ trypsin, pelleted and replated as single cells in "N2B27 medium" [1 part DMEM/F12 + 1 part Neurobasal medium, supplemented with N2 and B27, 2 mM Gluta max, $100 \mu \mathrm{M} \beta$ mercaptoethanol, $7.5 \mu \mathrm{g} / \mathrm{mL}$ insulin, $50 \mu \mathrm{g} / \mathrm{mL}$ bovine serum albumin (BSA)] at a density of $10,000 \mathrm{cells} / \mathrm{cm}^{2}$ on $10 \mathrm{~cm}$ Nunclon dishes coated for $2 \mathrm{~h}$ with $0.1 \%$ gelatin. Medium was changed every other day. On Day 7 , cells were treated with $0.05 \%$ trypsin for $1 \mathrm{~min}$, resuspended with N2B27 medium and fil tered through a $70 \mu \mathrm{m}$ cell strainer into $50 \mathrm{~mL}$ polypropylene tubes 
prefilled with phosphate buffered saline (PBS) to dilute trypsin. After centrifugation at $500 \mathrm{~g}$ for $3 \mathrm{~min}$, all cells were plated onto gelatin coated T75 Nunclon flasks in N2B27 medium supplemented with $20 \mathrm{ng} / \mathrm{mL}$ FGF2 and $20 \mathrm{ng} / \mathrm{mL}$ EGF. For cryopreservation, cells were trypsinized and cryopreserved in FBS containing 10\% DMSO at $2 \times 10^{6}$ cells $/ \mathrm{mL}$.

\section{Maintenance and Selection of NSC From Freshly Prepared d7NSC}

After 7 days neural induction of mESC, cells were grown in N2B27 medium supplemented with EGF and FGF2. The cells in these initial cultures had different morphologies and cell cycling behavior, some of them growing faster than others. Since the desired bipolar, RC2 positive NSC can be rare at Passage 1, cultures were not passaged until they reached full confluency ( $\sim 1$ week). To get rid of aggregating cells, which sit on top of other cells, plates were tapped several times to detach them mechanically before trypsinization. Some aggregating cells are usu ally in closer contact with other cells as well as the coated surface; therefore they cannot be removed by tapping the flasks. They were manually scratched with an aspiration pipette (aggregates are visible with the naked eye) and the borders of the flask were scratched as well. To separate bipolar NSC from triangular flat cells, cultures were treated with trypsin for only $1015 \mathrm{~s}$. Under these conditions, NSC detach in contrast to the more adherent triangular cells. Pic tures before and after mechanical cleaning and selective trypsiniza tion are shown in the Supporting Information Fig. S2. After trypsinization, the flask surface was washed only once with N2B27 medium to harvest bipolar NSC and avoid detaching triangular cells. The harvested cells were thoroughly resuspended in one cor ner of the flask to obtain single cells. Since NSC are very sensitive to trypsin, the cell suspension was directly diluted in about $20 \mathrm{~mL}$ PBS (through $70 \mu \mathrm{m}$ cell strainer), centrifuged rapidly afterward, and resuspended in medium. After several passages, the aggregating and the triangular cells disappeared. At about Passages 8 12, cultures purely consisted of bipolar NSC. Sometimes aggregating cells reappeared after Passage 8 , but they were easily removed as described above. Notably, NSC do not tend to aggregate when pas saged twice a week at the right density. They should not be seeded at less than 10,000 cells per $\mathrm{cm}^{2}$ and should be passaged at maxi mum $90 \%$ confluency (70 $80 \%$ confluency is better). For mainte nance culture, flasks with at least $75 \mathrm{~cm}^{2}$ should be used, since NSC tended to clump in smaller flasks.

\section{Astrocyte Differentiation}

NSC cultures from Passage 8 or later at $80 \%$ confluency were treated with $0.05 \%$ trypsin for $1015 \mathrm{~s}$, resuspended in N2B27 medium and filtered through a $70 \mu \mathrm{m}$ cell strainer prefilled with PBS, centrifuged (500g, $3 \mathrm{~min}$ ), and resuspended in medium. Cells were plated at a density of 30,000 (e.g., for NFkB translocation) to 50,000 (e.g., for metabolic studies) cells $/ \mathrm{cm}^{2}$ in N2B27 medium supplemented with $20 \mathrm{ng} / \mathrm{mL}$ bone morphogenetic protein 4 (BMP4). Nunclon dishes or plates were coated with $10 \mu \mathrm{g} / \mathrm{mL}$ poly $\mathrm{L}$ ornithine hydrobromide in $\mathrm{PBS}$ for $2 \mathrm{~h}$ at $37^{\circ} \mathrm{C}$, washed twice with PBS, and coated with $2 \mu \mathrm{g} / \mathrm{mL}$ laminin in PBS overnight.
Laminin was aspirated and the cell suspension was added to dishes/ plates. Medium was changed every other day from Day 1 and experiments were performed at Day 3 or 5 of differentiation. If cells were cultured for longer periods, medium was changed every other day using N2B27 medium with $10 \mathrm{ng} / \mathrm{mL}$ BMP4.

\section{Preparation and Maintenance of Primary Astrocytes} $\mathrm{BALB} / \mathrm{c}$ mice were bred at the animal facility of the University of Konstanz (Konstanz, Germany). All mice were housed at $22^{\circ} \mathrm{C}$ and $55 \%$ relative humidity in a $12 \mathrm{~h}$ day/night rhythm with free access to food and water according to national regulations and EU guide line 2010/63/EU. Primary astrocytes were prepared from 1 to 2 days old mouse pups as described earlier (Henn et al., 2011). Briefly, cells were prepurified by a percoll density gradient centrifugation right after dissociation of the cortices. The enriched astrocyte fraction was kept in tissue culture flasks for two weeks in medium containing $20 \%$ FBS. Then, they were trypsinized and plated for experiments.

\section{Quantitative Reverse Transcription Polymerase Chain Reaction}

Total RNA was isolated using PeqGold TriFast (Peqlab, Erlangen, Germany) according to the manufacturer's instructions and $1 \mu \mathrm{g}$ of RNA was reverse transcribed to complementary DNA (cDNA) using the iScript reverse transcription polymerase chain reaction (RT PCR) Supermix kit (Biorad). Quantitative RT PCR (qPCR) to mea sure mRNA expression levels was performed using a CFX96 ${ }^{\mathrm{TM}}$ Real Time System (BioRad, Hercules, CA) and SSO Fast EvaGreen Supermix (Biorad) according to the manufacturer's protocol. The cDNA levels relative to the housekeeping gene Gapdh were calcu lated using the delta $\mathrm{C}_{\mathrm{T}}$ method. Primers used are listed in the Sup porting Information.

\section{Immunofluorescence Staining and EdU Labeling}

Cells were fixed for $10 \mathrm{~min}$ with ice cold $90 \%$ methanol at $20^{\circ} \mathrm{C}$, permeabilized with $0.1 \%$ Triton X 100 in PBS at RT for $10 \mathrm{~min}$, and blocked for $30 \mathrm{~min}$ in 1\% BSA in PBS. Cells were stained with pri mary antibodies for $2 \mathrm{~h}$ and the respective secondary antibodies (Invi trogen, Darmstadt, Germany) for $50 \mathrm{~min} .1 \mu \mathrm{g} / \mathrm{mL} \mathrm{H} 33342$ was added during the last 20 min to counterstain DNA. Primary antibod ies used are listed in the Supporting Information. To detect DNA syn thesis, cells were incubated for $48 \mathrm{~h}$ with the thymidine analogue EdU (Baseclick, BCK EdU555), fixed and permeabilized as described above, and stained according to the manufacturer's instruction.

\section{Microarray Profiling and Data Analysis}

RNA of four independent cultures and differentiations of mESC, NSC, and 5 day old mAGES was isolated from three pooled techni cal replicates as described for qPCR. Microarray analysis was con ducted as described earlier (Krug et al., 2013). Briefly, $12.5 \mu \mathrm{g}$ fragmented aRNA was hybridized with Affymetrix Mouse Genome 4302.0 arrays according to the manufacturer's instructions. All reagents and instruments were acquired from Affymetrix (Affymetrix, Santa Clara, CA). The generated CEL files were used for further sta tistical analysis. All microarray datasets were preprocessed using the GC RMA procedure for background correction, quantile 
normalization and probe replicate summarization (Wu et al., 2004). All statistical analyses were performed in the R Statistical Program ming Environment (Ihaka and Gentleman, 1996). Differentially expressed genes between pairs of conditions were determined using the Empirical Bayes moderated t statistic (Smyth, 2004) and adjusted for multiple hypothesis testing using the Benjamini Hochberg method (Benjamini and Hochberg, 1995). A false discovery rate threshold of 0.05 was chosen to determine the signifi cantly differential genes.

\section{Protein Measurement and LDH Release}

Cells were lysed in $2 \%$ sodium dodecyl sulfate (SDS) and protein content of lysates was measured using Pierce ${ }^{\mathrm{TM}}$ BCA Protein Assay Kit (Thermo Scientific) according to the manufacturer's protocol. For the release of lactate dehydrogenase (LDH), $10 \mu \mathrm{L}$ (one tenth of total volume) of supernatant and cell lysates $(20 \mathrm{~min} 0.1 \%$ Triton $\mathrm{X} 100)$ were used together with $200 \mu \mathrm{L}$ reaction mix containing 1:50 pyruvate to $\mathrm{NADH}$ reagent $(68 \mu \mathrm{g} / \mathrm{mL}$ pyruvate in $\mathrm{KPP}$ buffer (40.24 mM K $\mathrm{HPO}_{4}, 9.7 \mathrm{mM} \mathrm{KH} \mathrm{PO}_{4}, \mathrm{pH} 7.5$ ) and $8.47 \mathrm{mg} / \mathrm{mL}$ $\mathrm{NADH}$ in $1 \% \mathrm{NaHCO}_{3}$ ). NADH oxidation was measured at $340 \mathrm{~nm}$ with BioTek EL808 Absorbance Reader for $20 \mathrm{~min}$. LDH release in percent was calculated from $\Delta \mathrm{OD}_{340}$ (supernatant)/ $\left(\Delta \mathrm{OD}_{340}\right.$ (supernatant) $+\Delta \mathrm{OD}_{340}$ (lysate) $)$.

\section{Glutamate Uptake Measurement}

Cells were preincubated with Hanks' Balanced Salt Solution (HBSS, Gibco) containing $1 \mathrm{~g} / \mathrm{L}$ glucose. After $30 \mathrm{~min}, 10 \mu \mathrm{M}$ L glutamic acid (G1624, Sigma) was added supplemented with $0.12 \mu \mathrm{Ci} \mathrm{L}$ $\left[3,4{ }^{3} \mathrm{H}\right]$ glutamic acid (PerkinElmer, NET490250UC) per sample. After 8 min, cells were washed 4 times with HBSS and lysed with $0.5 \%$ Triton X100 for 30 min. Lysates were mixed 1:1 with Ultima Gold AB scintillation cocktail (PerkinElmer, G013309) and meas ured with the LS 6500 scintillation counter (Beckman Coulter).

\section{Culture Condition for Metabolic Flux Analysis and Metabolite Extraction}

NSC and mAGES were seeded in six well plates in their normal condition. NSC were maintained 2 days until they were about $60 \%$ confluent and mAGES were differentiated until Day 5. Cells were washed twice with prewarmed PBS and incubated in N2B27 medium without glucose [1:1 Neurobasal A and Advanced DMEM/ F 12] supplemented with $10 \mathrm{mM} \mathrm{D}\left[1{ }^{13} \mathrm{C}\right]$ glucose for $0,0.3,3$, 12 , and $24 \mathrm{~h}$. Medium was collected, centrifuged at $200 \mathrm{~g}$ for 10 min, and supernatant was frozen at $20^{\circ} \mathrm{C}$ until further processing. Cells were washed twice with ice cold PBS, frozen in liquid nitro gen, and extracted with $70 \%$ ethanol. After centrifugation of the cell extracts for $15 \mathrm{~min}$ at $20,000 \mathrm{~g}$, supernatants were collected and stored at $80^{\circ} \mathrm{C}$ until further analysis. Pellets were stored at $20^{\circ} \mathrm{C}$ for protein determination.

\section{Measurement of Glucose, Lactate, and Amino Acids in Supernatant}

Glucose and lactate concentrations in samples of cell supernatants were determined using an automated YSI 7100 Multiparameter Bio analytical System (Dayton, OH). Extracellular concentrations of amino acids were quantified by HPLC using a precolumn derivatiza tion method based on the Waters AccQ Tag Amino Acid Analysis method as described elsewhere (Amaral et al., 2010).

\section{Quantification of Mass Isotopomers by GC-MS}

Analysis of ${ }^{13} \mathrm{C}$ percent enrichment in metabolites was carried out by redissolving lyophilized extracts in $0.01 \mathrm{M} \mathrm{HCl}$. Samples were extracted in multiple steps into an organic phase of ethanol and ben zene and lyophilized before derivatization with $N$ methyl $N$ (t butyldimethylsilyl)trifluoroacetamide $+1 \%$

butyldimethylchlorosilane (MTBSTFA). The samples were analyzed on an Agilent 6890 gas chromatograph (GC) connected to an Agi lent 5975B mass spectrometer (MS) (Agilent Technologies, Palo Alto, CA). The parent ion (M) and atom percent excess for one, two, $\mathrm{n}{ }^{13} \mathrm{C}$ atom $(\mathrm{M}+1,2, n)$ values for metabolites were calculated from GC MS data using MassHunter software supplied by Agilent (Agilent Technologies) and corrected for the naturally abundant ${ }^{13} \mathrm{C}$ by using nonenriched standards (Walls et al., 2014).

\section{${ }^{1} \mathrm{H}$-NMR Spectroscopy for Citrate Determination in Cell Culture Supernatants}

Citrate concentration in samples of cell supernatants was determined by ${ }^{1} \mathrm{H}$ NMR spectroscopy, in a $500 \mathrm{MHz}$ Avance spectrometer (Bruker, Billerica, MA) with a $5 \mathrm{~mm}$ QXI probe. Spectra were recorded at $25^{\circ} \mathrm{C}$, using a NOESY based pulse sequence with water presaturation, performing 256 scans, with $4 \mathrm{~s}$ acquisition time and 2 s relaxation delay. DSS d6 (Sigma Aldrich, St. Louis, MO) was used as internal standard. Samples were mixed with phosphate buffer ( $\mathrm{pH}$ 7.4) prepared in $\mathrm{D}^{2} \mathrm{O}$ at a 2:1 ratio. Each spectrum was phased, baseline corrected, and integrated using the Chenomx NMR Suite 7.1 (Chenomx, Canada) software.

\section{Cell Stimulation, NFkB Translocation, and interleukin 6 ELISA}

Cells were stimulated with the complete cytokine mix (CCM) con taining $10 \mathrm{ng} / \mathrm{mL}$ tumor necrosis factor $\alpha(\mathrm{TNF} \alpha), 10 \mathrm{ng} / \mathrm{mL}$ inter leukin $1 \beta$ (IL $1 \beta$ ), and $20 \mathrm{ng} / \mathrm{mL}$ IFN $\gamma$ (R\&D Systems, Wiesbaden, Germany) or with its single components for $30 \mathrm{~min}$ in case of NFkB staining, $4 \mathrm{~h}$ for qPCR measurements, or $8 \mathrm{~h}$ for IL 6 measurement in the respective medium. For NFkB measurement, cells were fixed, permeabilized and stained for NFkB. NFkB translo cation was measured with the high throughput device Cellomics ArrayScan or CellInsight ${ }^{\mathrm{TM}}$ CX5 High Content Screening (Thermo Scientific) using the nuclear translocation algorithm as described pre viously (Henn et al., 2011). Supernatants for IL 6 ELISA were col lected and stored at $80^{\circ} \mathrm{C}$ until further processing. IL 6 was measured in supernatants diluted 1:5 in assay diluent and mouse IL 6 ELISA Ready SET Go was performed according to the manufac turer's protocol (eBioscience).

\section{Results}

Pivotal Conditions for the Generation of Astrocytes from ESC-Derived Neural Stem Cells

Embryonic stem cells were differentiated within 7 days into neural stem cells of distinct morphologies, when plated on 
gelatin coated dishes in N2B27 medium without growth fac tors. The cells had a high nestin expression and neurogenic potential as described previously (Conti et al., 2005; Zimmer et al., 2011a,b). However, they hardly generated astrocytes when exposed to bone morphogenetic protein 4 (BMP4) (Supp. Info. Fig. S1A), serum, CNTF, or combinations thereof (not shown). The morphologically heterogeneous neu ral stem cell population contained bipolar cells in addition to other cell types (Supp. Info. Figs. S1B and S3). Maintenance of the cells in EGF and FGF2 containing medium for several passages, and removal of aggregate forming as well as flat, tri angular cells (selective trypsinization/mechanical cleaning) at each passage step produced a homogeneous population of bipolar cells (Supp. Info. Fig. S2). These "secondary NSC" could be completely converted to GFAP positive, nestin negative (about $80 \%$ of the cells only showed background staining after 3 days) astrocytes upon BMP4 exposure (Supp. Info. Fig. S1A). The pivotal step in the production of "murine astrocytes generated from embryonic stem cells" (mAGES) was the selection of an astrogenic cell population, which could then be easily maintained for at least 40 passages or frozen, banked, and re thawed for subsequent differentia tion (Fig. 1A).

The secondary NSC (=high passage NSC) still retained their potential to generate mature neurons within 14 days, when growth factors were withdrawn from the medium (Supp. Info. Fig. S4). Thus, NSC are multipotent neural stem cells, which give rise to astrocytes as well as neurons. This also held true for single cell clones: Ten out of 10 clones generated mAGES after 5 days of BMP4 exposure, with only slight morphological differences (Supp. Info. Fig. S5). More over, when differentiated without growth factors, all of the clones generated about $60 \%$ neurons.

Astrogenic NSC have been produced five times from the mESC cell lines CGR8.0 and E14, and astrocytes have been generated from these with the same efficiency (not shown). Furthermore, mESC lines from a different mouse background (DO335 and BTBR) or murine induced pluripo tent stem cells (iPSC) have been used successfully for mAGES generation (Supp. Info. Fig. S6). Expression of GFAP, Aqp4, and nestin in mAGES produced therefrom was similar to the one found in the control line CGR8.0. This broad applicabil ity confirmed the robustness of the astrocyte differentiation protocol.

\section{Rapid Generation of Mature Astrocytes From NSC}

To characterize the cells, well known markers were quantified for NSC as well as mAGES on mRNA level by quantitative PCR. Expression levels were compared with those of primary murine astrocytes. As previously reported, NSC expressed the neural stem cell markers Nestin, the brain lipid binding pro tein Blbp, and the oligodendrocyte transcription factor Olig2 (Conti et al., 2005). All three genes were downregulated in mAGES after differentiation for 5 days with BMP4 (Fig. 1B). The expression of Blbp and Olig2 was similar in primary astrocytes and mAGES, while Nestin expression was more than 100 fold lower in mAGES compared with NSC or pri mary astrocytes. Other genes, which are normally expressed in both neural stem cells and astrocytes, like the glutamine synthetase (Glul) and the glutamate aspartate transporter (Glast), were similarly expressed in all three cell types (Fig. 1B).

The astrocytic glial fibrillary acidic protein (Gfap) was highly expressed in mAGES as well as in primary astrocytes, whereas it was absent in NSC (Fig. 1C). The calcium binding protein $S 100 b$, another well known astrocyte marker, was highly expressed in all three cell types. Aquaporin 4 (Aqp4) and the glutamate transporter Glt-1, both specific markers for mature astrocytes, were upregulated in mAGES and primary astrocytes compared with NSC. Also, the alde hyde dehydrogenase Aldh1L1, which is reported to be astrocyte specific in the brain (Cahoy et al., 2008), was expressed at eightfold higher levels in mAGES compared with NSC (Fig. 1C).

When the time course of marker expression was fol lowed during the conversion of NSC to mAGES, we found that dramatic changes (up to 1,000 fold) occurred within $24 \mathrm{~h}$ after BMP 4 addition. Gfap and Glt-1 reached their max imum level already after 1 day, whereas Aqp4 and Nestin fur ther increased/decreased from Day 1 to Day 3 of BMP4 exposure. No changes were observed from Day 3 to Day 5. This suggests that astrocyte differentiation was completed after 3 days (Fig. 1D). The cells could be easily maintained in this stage for at least 4 weeks (not shown).

As further differentiation characteristic, we investigated the proliferation state of mAGES. This endpoint was chosen, because fully differentiated, mature astrocytes hardly undergo spontaneous cell division (i.e., without stimulation by growth factors or serum), while immature cells and astrocytic precursors (as sometimes present in primary cultures or stem cell derived populations) have a relatively high proliferation rate. DNA repli cation was followed on single cell level by incorporation of the thymidine analogue 5 ethynyl $2^{\prime}$ deoxyuridine (EdU) into newly synthesized DNA. EdU was easily detected in the nuclei of NSC, whereas mAGES did not show any EdU incorporation at all during a $48 \mathrm{~h}$ incubation (Fig. 1E). Exact quantification showed that more than $90 \%$ of NSC incorporated EdU (prolif erating cells), while $<0.1 \%$ of mAGES proliferated (Fig. 1F).

\section{Factors Affecting Differentiation Efficacy}

Since a single positive marker, such as Gfap mRNA or GFAP protein expression is not sufficient to characterize the extent 
A

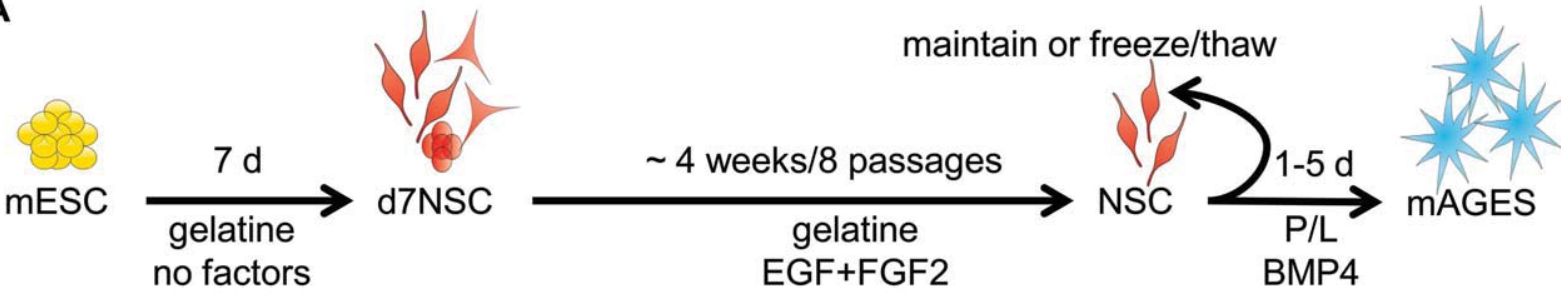

B
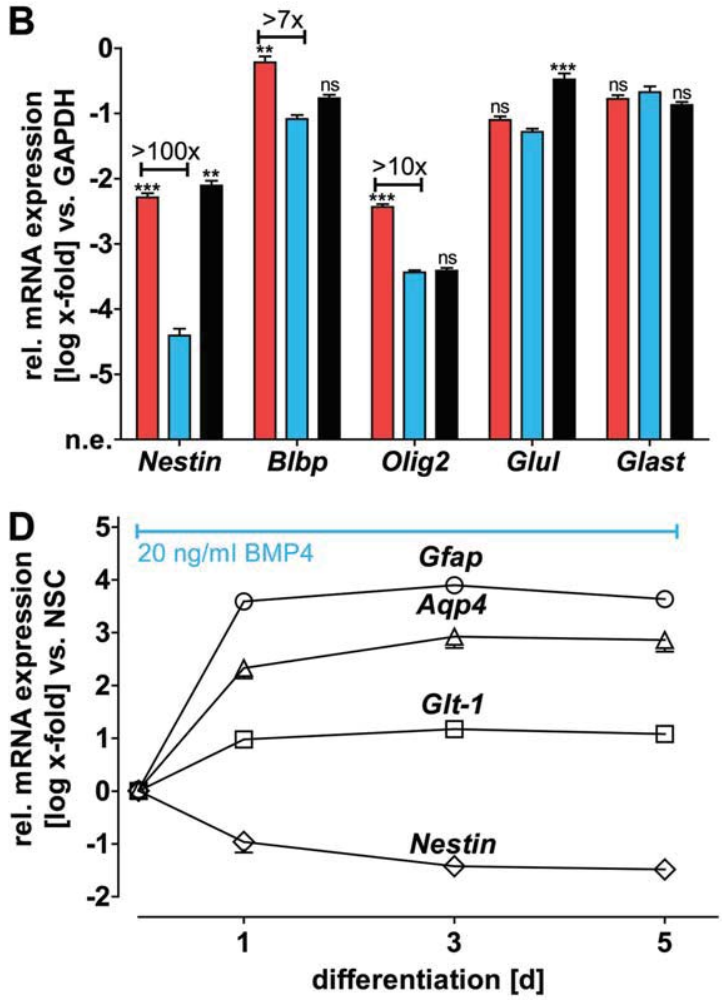

C

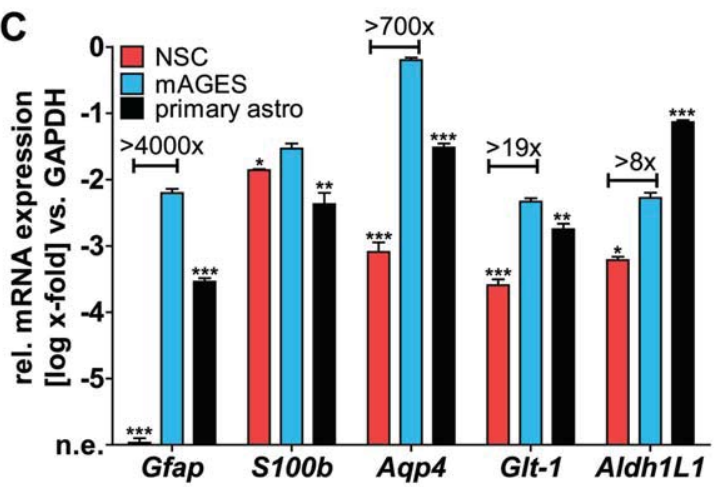

$\mathbf{E}$
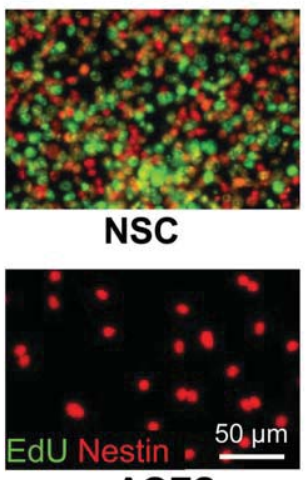

mAGES

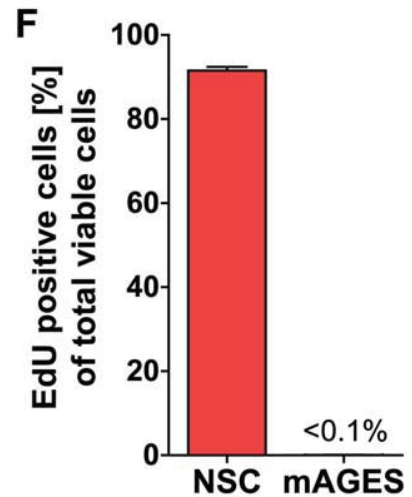

FIGURE 1: Rapid generation of nonproliferating, mature astrocytes from neural stem cells. (A) A heterogeneous population of "neural stem cells" (d7NSC) was generated within 7 days by spontaneous differentiation of murine embryonic stem cells (mESC). Selective pas saging (at least 812 times) in the presence of $20 \mathrm{ng} / \mathrm{mL}$ EGF and FGF2 on gelatine produced a homogeneous population of NSC that could be frozen for later use or maintained by further passaging. Transfer of the cells to poly ornithin/laminin (P/L) coated dishes and exposure to BMP4 $(20 \mathrm{ng} / \mathrm{mL})$ resulted in the generation of murine astrocytes generated from $\mathrm{mESC}$ (mAGES). (B and C) For measure ments of gene expression by qPCR, mRNA was prepared from mAGES (after 5 days of differentiation), NSC or primary murine astro cytes. All data are given in fold difference ( $x$ fold) relative to the housekeeping gene Gapdh (note logarithmic axis scaling). The horizontal brackets in the plots indicate the fold difference of mAGES vs. NSC (B) Nestin, Blbp (FABP7, brain lipid binding protein), Olig2 (oligodendrocyte lineage transcription factor; neuroectodermal marker), Glul (Glutamine synthetase) and Glast (Slc1A3; glutamate transporter) were used as NSC markers; (C) Gfap (glial fibrillary acidic protein), S100b (S100beta), Aqp4 (aquaporin), Glt 1 (Slc1A2, glu tamate transporter), and Aldh1L1 (aldehyde dehydrogenase) were used as astrocyte markers (D) NSC were exposed to $20 \mathrm{ng} / \mathrm{mL}$ BMP4 and left to differentiate to mAGES. At the times indicated, mRNA was prepared to quantify the expression of marker genes by qPCR. All data are given relative to the expression in NSC ( $\log _{10}$ scaled), based on the $\Delta \Delta C_{T}$ method. Data are means \pm SEM from three experi ments (some error bars are smaller than the symbols). ${ }^{* \star} P<0.0001 ;{ }^{*} P<0.001 ;{ }^{*} P<0.01$ (one way ANOVA with Dunnett's post hoc test). (E) NSC and mAGES ( 3 days old) were incubated with the nucleoside analogue EdU (10 $\mu \mathrm{M})$ for $48 \mathrm{~h}$, before cells were fixed. Then, EdU incorporation was visualized by immunocytochemistry, and nuclei were counterstained with $\mathrm{H} 33342$ (note that EdU staining (dark green) appears yellow to green, depending on the strength of the always underlying $\mathrm{H} 33342$ (red) stain) (F) The number of nuclei that were EdU positive were counted in NSC and mAGES cultures by an automated screening microscope (1,000 nuclei/condition). The data displayed are means \pm SEMs from three independent experiments. In mAGES cultures less than 1 cell per condition was found to be EdU positive (<0.1\%). [Color figure can be viewed in the online issue, which is available at wileyonlinelibrary.com.]

of astrocyte differentiation, we chose here to measure GFAP, nestin (protein expression) and EdU incorporation (DNA synthesis) to compare different inducers of differentiation. BMP4, as used in our optimized protocol, led to a complete cell cycle exit, a high percentage of GFAP positive cells and a $>80 \%$ reduction of nestin positive cells. When fetal bovine serum (FBS) was used instead of BMP4, NSC differentiated to mAGES with a similar GFAP expression, but nestin 
expression was higher (Supp. Info. Fig. S7). Moreover, some mAGES were still proliferating, as indicated by EdU incorpo ration. Other cytokines, such as LIF or CNTF were not able to induce complete mAGES differentiation. Although GFAP was upregulated under these conditions to a high extent, the cells had a high nestin expression and proliferation rate. Moreover, the morphology was not typical of astrocytes (Supp. Info. Fig. S7). These findings showed that GFAP alone is not sufficient to judge the differentiation to mature astrocytes, and that BMP 4 was the most efficient agent, when several parameters were considered.

Finally, we were interested in whether the protocol allowed the identification of factors that negatively affect astrocyte differentiation (e.g., developmental toxicants). Sev eral poisonous compounds known to affect neurodevelopment (e.g., methylmercury, manganese) were added during the dif ferentiation procedure, and the expression (immunocytochem istry) of GFAP, Aqp4, and nestin was evaluated as endpoint. None of the toxicants affected mAGES generation, when used at noncytotoxic concentrations. The same applied to small molecules, which are known to inhibit BMP4 induced SMAD signaling (e.g., dorsomorphin or LDN 193189), indi cating that canonical SMAD signaling was not required for the differentiation of mAGES. From this we conclude that the protocol developed here is very robust toward many exter nal disturbances. In the search for positive examples of devel opmental disturbances, we used two harsh approaches: (i) addition of noggin, which neutralizes BMP4, inhibited upreg ulation of GFAP as well as downregulation of nestin (data not shown) and (ii) very high concentrations of valproic acid (VPA, $10 \mathrm{mM}$ ), an HDAC inhibitor and neurodevelopmental toxicant, reduced mAGES generation, although they were not directly cytotoxic to astrocytes (Supp. Info. Fig. S8). Thus, identification of chemicals or hormonal factors that inhibit astrocytogenesis seems to be feasible in this system.

\section{Basic Metabolic Features of mAGES vs. NSC}

Relatively little is known yet about metabolic differences and similarities of astrocytes and their immediate precursors. In 2004, Brunet and others used murine neural stem cells differ entiating to astrocytes in order to ask the question, at which developmental stage typical metabolic features of astrocytes are developed (Brunet et al., 2004). This elegant study pro vided initial evidence on metabolic differences between NSC and astrocytes. For example the maximum glutamate trans port capacity changed during astrocytogenesis, but the line of work was unfortunately not continued and metabolic conse quences for the cells are not known. As both mAGES and NSC expressed glutamine synthethase, we were interested in its cellular metabolic integration. As an integrative endpoint for this, we studied cell survival in medium supplemented with glutamine or not. In mAGES, the protein content per well (as viability parameter) and LDH release (as direct cell death measure) did not change within a $24 \mathrm{~h}$ period in either condition. Thus, the absence of glutamine did not trigger cell death (Fig. 2A,B). In fact, mAGES could be cultured for at least 4 days in glutamine free medium without changes in viability (data not shown), confirming their independence from exogenous glutamine. By contrast, NSC were strongly dependent on glutamine, i.e., protein content per well decreased and LDH release increased already at $12 \mathrm{~h}$ after withdrawal from glutamine.

To get an overview on central energy metabolism, glu cose uptake and lactate release rates were determined. NSC had nearly a twofold metabolic rate (increased glucose con sumption as well as lactate release) compared with mAGES (Fig. 2C,D). Altogether, both cell types had a high glucose to lactate conversion rate, and thus a minor contribution of mitochondrial metabolism (Fig. 2E,F), which is typical for stem cells (Candelario et al., 2013; Teslaa and Teitell, 2015), and astrocytes (Amaral et al., 2011; Magistretti et al., 1999; Waagepetersen et al., 1998). Thus, mAGES and NSC share some basic metabolic features, while differences became evi dent in glutamine free environment, where only mAGES survived.

\section{Immunocytochemical Phenotyping of NSC and mAGES as Homogeneous Populations of Neural Stem Cells and Astrocytes}

After having established basic metabolic features and mRNA marker expression patterns in NSC and mAGES cell popula tions, we investigated the homogeneity of the two cultures on single cell resolution by immunocytochemistry. While all NSC expressed NESTIN, most mAGES (>80\%) downregu lated its expression to background levels, and some cells retained a weak expression. All NSC stained positive for the radial glia marker $\mathrm{RC} 2$, while this protein was absent in mAGES. GLAST was expressed to varying levels in NSC (heterogeneous staining pattern), and to a much lower extent in mAGES. The calcium binding protein S100B was detected in both cell types, consistent with similar mRNA levels (Fig. 3A).

The "astrocytic" intermediate filament protein GFAP was strongly and ubiquitously (>99\%) expressed in mAGES, but not in NSC $(<1 \%)$. The same was observed for the glu tamate transporter GLT 1. About $70 \pm 7 \%$ of mAGES expressed AQP4 (to various extents), while this protein was absent in NSC. The morphology of NSC changed dramati cally when exposed to BMP4 for 3 days. All of the small, bipolar NSC cells adopted the typical star shaped/feathery morphology of astrocytes with radial processes and a flattened appearance, when differentiated to mAGES (Fig. 3B). To 

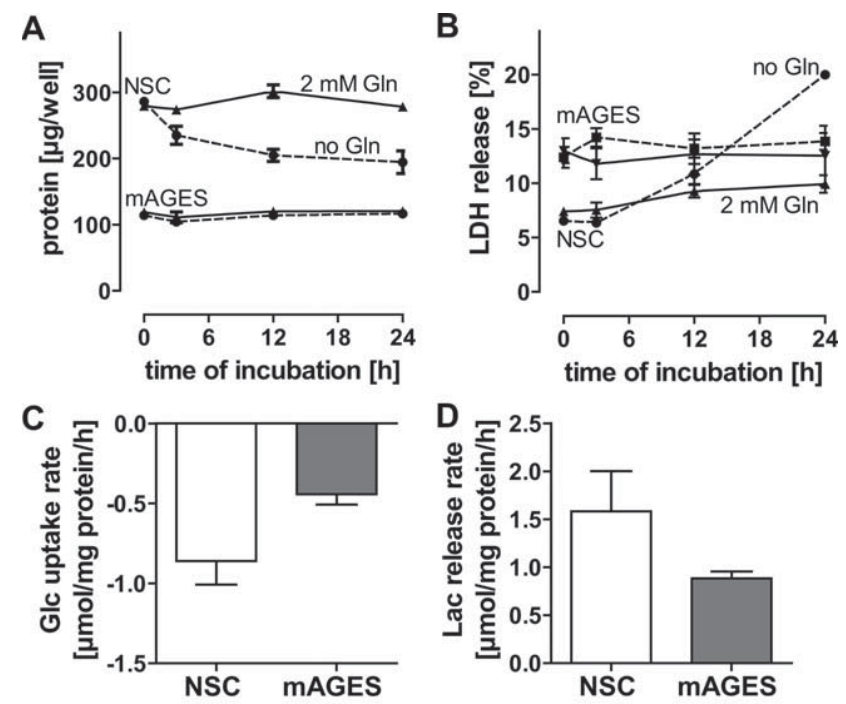

E

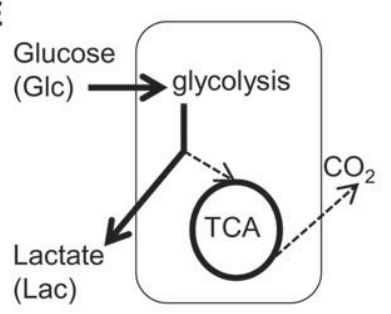

NSC were converted to a highly homogeneous population of astrocytes, containing no detectable proliferating precursor cells, or GFAP negative cells, and displaying heterogeneity for Aqp4, as observed in brain tissue.

\section{Whole Transcriptome-Based Characterization of mAGES and Their Relationship to NSC}

Only relatively recently, transcriptome data for astrocytes have become available to characterize their gene expression levels in different brain regions, culture conditions, and as opposed to neurons or oligodendrocytes (Cahoy et al., 2008; Lovatt et al., 2007; Shaltouki et al., 2013). However, little is known about the relationship of astrocytic and NSC gene expression, in particular for murine cells as major model system. There fore, expression of over 34,000 genes (covered by 45,000 pro besets) was measured here by microarray profiling. For each cell type (mAGES, NSC, mESC), mRNA was prepared from four independent differentiations, and principal component analysis of global gene expression revealed significant differen ces between all three cell types (Fig. 4A).

Quantitative comparison of gene expression allowed the identification of differentially expressed genes (DEG) for the different developmental stages, and more than 3,000 genes differed at least twofold between the cell types with an adjusted $P$ value cutoff $<0.05$. The most substantial change occurred during mESC to NSC differentiation with more than 10,000 DEG between the two cell populations. Most importantly for the present study, we found that NSC and mAGES differed in more than 7,000 genes. Thus, although mAGES and NSC are developmentally and functionally related, these data show their considerable disparity (Fig. 4B).

To identify marker genes, we performed pairwise com parisons of mESC, NSC, and mAGES, and the top 20 up or downregulated genes of each comparative analysis, sorted by $P$ value significance or fold change, were compiled (Supp. Info. Fig. S10). During development of mESC to NSC, many genes involved in nervous system development were upregulated, some of them (e.g., Olig1/2, Ptn (pleiotrophin) or Gpm6a (calcium channel related to neurogenesis)) more than 1,000 fold. The top 20 downregulated genes coded for factors essential for the maintenance of embryonic stem cells, such as Zfp42, Nanog, Oct4 (Pou5fI), Fgf4, and Lefty2 (Supp. Info. Fig. S9).

The top 20 genes (according to the significance of regu lation) in mAGES compared with NSC included $I d I$ and Id4. These may not necessarily be cell type specific markers, as they are triggered by the BMP4 present in our cultures, but they are also known to play a role in astrocytogenesis (Fig. 4C). The highest upregulated gene in mAGES com pared with NSC was fibromodulin (Fmod), which was more than 6,000 fold changed. The corresponding protein has 

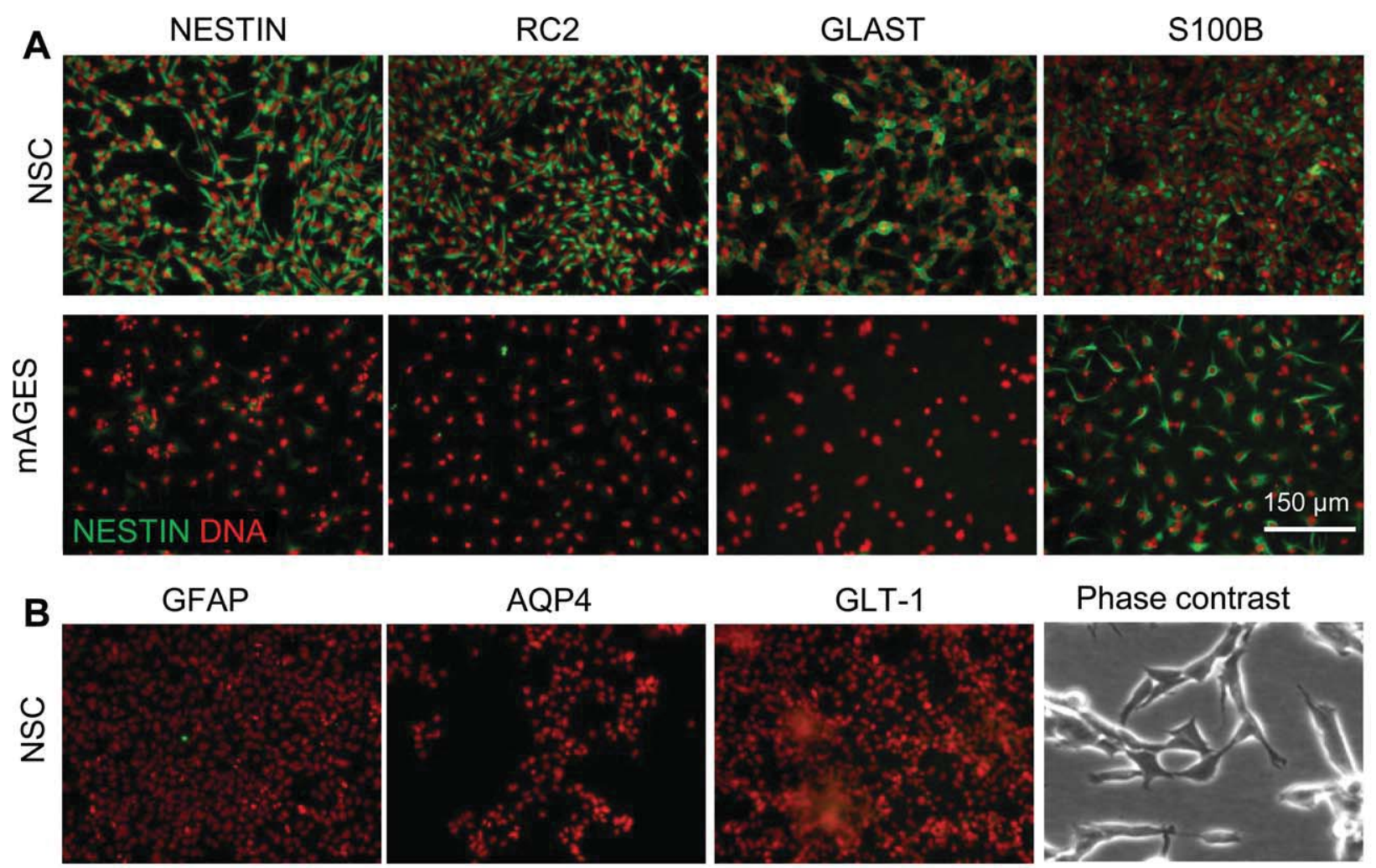

\section{Phase contrast}
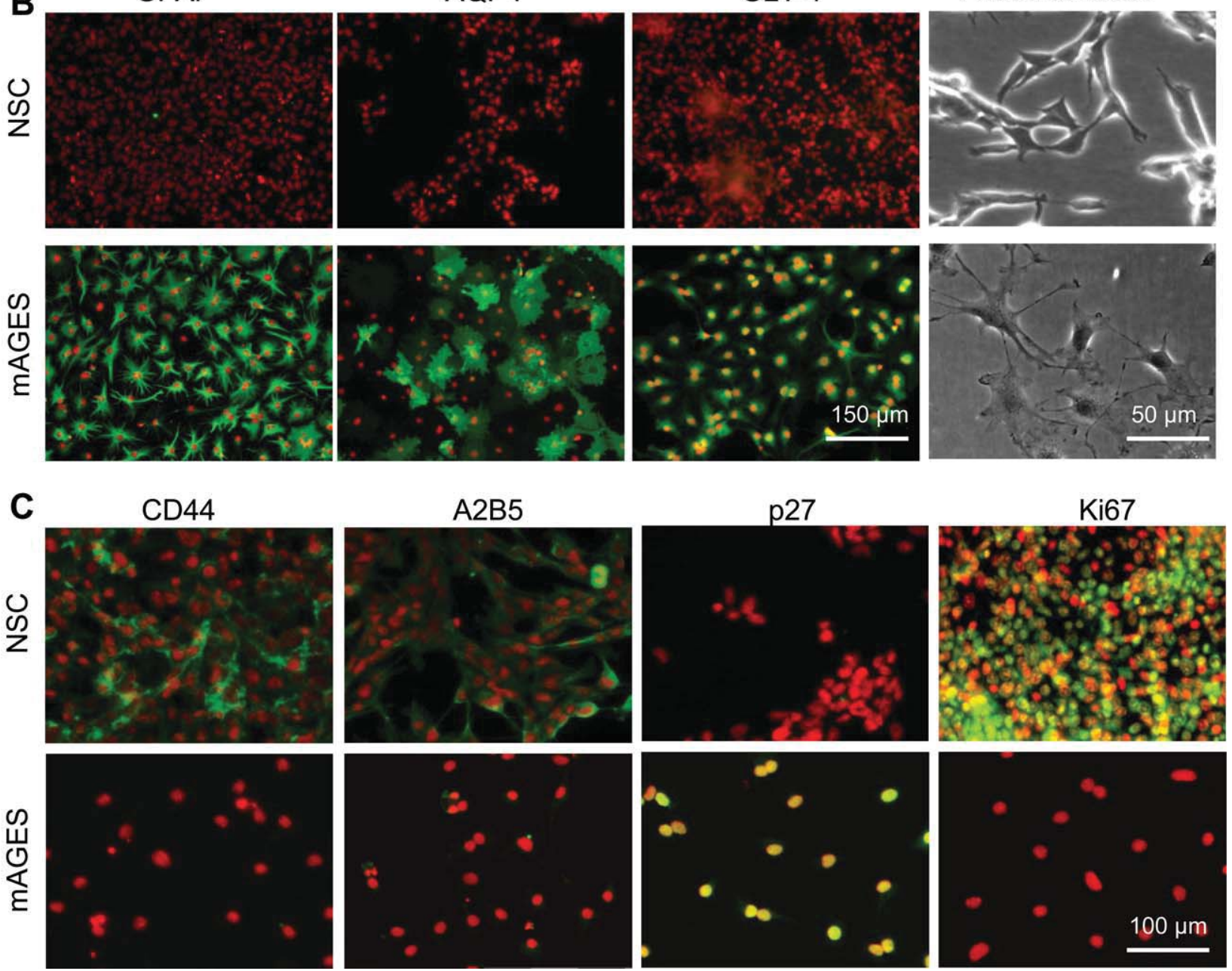

FIGURE 3: Immunocytochemical characterization of marker expression and cell culture homogeneity of NSC and mAGES. NSC and mAGES ( 3 days old) were fixed and permeabilized. Marker proteins (green) were visualized by immunocytochemistry and nuclei were counterstained with H 33342 (red). (A) NESTIN, RC2 (radial glia marker), GLAST (glutamate transporter), and S100B were used as NSC marker proteins. (B) GFAP (glial fibrillary acidic protein), AQP4 (aquaporin 4), and GLT 1 (glutamate transporter) were used as markers for mature astrocytes. Phase contrast pictures were taken from living cells before fixation. (C) CD44 and A2B5 were used as astrocyte precursor markers. The cell cycle inhibitor (p27) and the proliferation marker Ki67 were used to examine the cell cycle status of NSC and $\mathrm{mAGES}$. [Color figure can be viewed in the online issue, which is available at wileyonlinelibrary.com.] 
metabolic functions and is involved in extracellular matrix organization. We also found genes involved in development (Aplnr, Ndrg4), chemotaxis (Cxcr7, Cmtm6), and immune response (Lyz1, Lyz2, Peli2). The top 10 upregulated genes were further validated by qPCR and the data confirmed that all of them were much higher expressed in mAGES compared with NSC (Supp. Info. Fig. S12A,B). When DEG of mAGES against NSC were sorted by fold change, then the top 20 list comprised the well known astrocyte marker genes Gfap and Aqp 4. Furthermore, we found again genes involved in the heterogeneous functions of mature astrocytes, such as immune response, extracellular matrix organization, metabolic homeostasis, or angiogenesis. More than $70 \%$ of the genes, which were downregulated in mAGES vs. NSC, were related to the cell cycle (Fig. 4C,D). This is well in concordance with the cell cycle exit of mAGES. Since the top 20 DEG expressed genes in mAGES comprised several transcripts, which were not previously recognized to be cell type specific, we investigated their in vivo expression by using published microarray data on parenchymal astrocytes and adult neural stem cells (aNSC) from the subventricular zone (Beckervor dersandforth et al., 2010). Many of the genes upregulated in mAGES were also more prominent in mature astrocytes (Supp. Info. Fig. S13A). Moreover, all genes found to be downregulated in our study were much higher expressed in aNSC than in parenchymal astrocytes. Thus, the set of DEG found in our study seems to be suitable to distinguish astro cytes and NSC also in vivo. In summary, the gene expression profiles provide cell type specific signatures that enable a clear distinction between NSC and mAGES, and thus also a refined definition of respective cell specific functions.

\section{Comparison of mAGES Gene Expression With Different Other Cell Populations}

For further characterization of mAGES and NSC, we com pared their gene expression levels to legacy data and marker genes available from the literature. First, we compiled a list of genes specific for mESC, neural stem cells, and astrocytes (Cahoy et al., 2008; Kuegler et al., 2010). Amongst the 94 markers, 29 were for embryonic stem cells, 29 were consid ered specific for neural stem cells, and 36 for astrocytes.

Comparison of mAGES, NSC and mESC expression levels for these markers showed that all embryonic stem cell marker genes were indeed expressed most strongly in our mESC cultures (Fig. 4E). About half of the genes considered to be specific for murine neural stem cells had their highest expression in NSC. However, the other half was expressed to similar levels in mAGES. Almost all astrocyte markers had indeed their highest expression in mAGES (compared with mESC or NSC), only Glul expression was more prominent in NSC (Fig. 4E).
These findings corroborate the formation of genuine astrocytes from NSC by the mAGES differentiation protocol presented here, and they also confirm a close biological rela tionship between astrocytes and NSC. The need for re definition of an optimized marker set is also obvious from the data presented. For instance Fgfr 2 should rather be con sidered an astrocyte marker than an NSC marker.

To compare the microarray data of in vitro generated NSC and mAGES to primary brain cells, a heatmap of Spear man correlations was generated to illustrate relative similar ities and differences of the expression profiles of the 94 marker genes described above. First, data on different primary cultures of astrocytes, neurons, or oligodendrocytes, prepared at different days of development (Cahoy et al., 2008), were correlated with NSC and mAGES. The mAGES correlated best with primary astrocytes, and less with primary neurons or oligodendrocytes. The highest correlation was found with astrocytes from postnatal brains at Days 78 post partum. The NSC expression patterns only showed a modest correlation with any of the primary brain cells. They were most similar to developmentally early brain cells like postnatal astrocytes from post partum Day 1 mice or oligodendrocyte precursor cells, while the greatest difference was found between NSC and mature astrocytes or neurons (Fig. 5A).

As an alternative approach, expression profiles of mAGES were also compared with data obtained previously on primary cells from different brain regions (Doyle et al., 2008). Here, the highest correlation was observed for cortical astrocytes, while intermediate correlations were seen for cere bellar astrocytes and Bergmann glia, and the lowest correla tion was obtained for neuronal cultures (Fig. 5B).

\section{Divergent Biosynthetic Metabolism of NSC and mAGES}

A direct metabolic comparison of neural stem cells and astro cytes has been difficult so far, especially as different populations of surrounding cells (in their tissue context or in conventional cultures) make biochemical approaches very challenging. We used here the availability of the homogeneous and well characterized mAGES and NSC populations to obtain first evi dence on divergent metabolic features of such cells. As an established approach to study central carbon metabolism, we followed the incorporation of the nonradioactive ${ }^{13} \mathrm{C}$ isotope from $\mathrm{D}\left[1{ }^{13} \mathrm{C}\right]$ glucose into different cellular metabolites (Fig. 6A). As default condition, NSC and mAGES were cultured in medium, which was adapted to the respective basic cell func tions in vivo: mAGES were cultured without glutamine, similar to conditions chosen for metabolic flux analysis with glutamine producing primary astrocytes earlier (Amaral et al., 2011); NSC were cultured in the presence of $2 \mathrm{mM}$ glutamine, according to their metabolic requirement for an external 
A

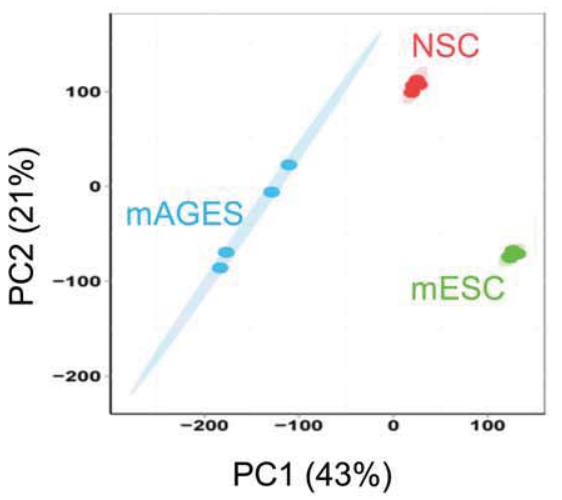

B

\begin{tabular}{|c|c|c|}
\hline DEG & up & down \\
\hline $\begin{array}{c}\text { NSCl } \\
\text { mESC }\end{array}$ & 7233 & 3074 \\
\hline $\begin{array}{c}\text { mAGESI } \\
\text { mESC }\end{array}$ & 4501 & 4861 \\
\hline $\begin{array}{c}\text { mAGES } / \\
\text { NSC }\end{array}$ & 3352 & 3743 \\
\hline
\end{tabular}

DEG: $F C \geq 2, p<0.05$

C fold change upregulated

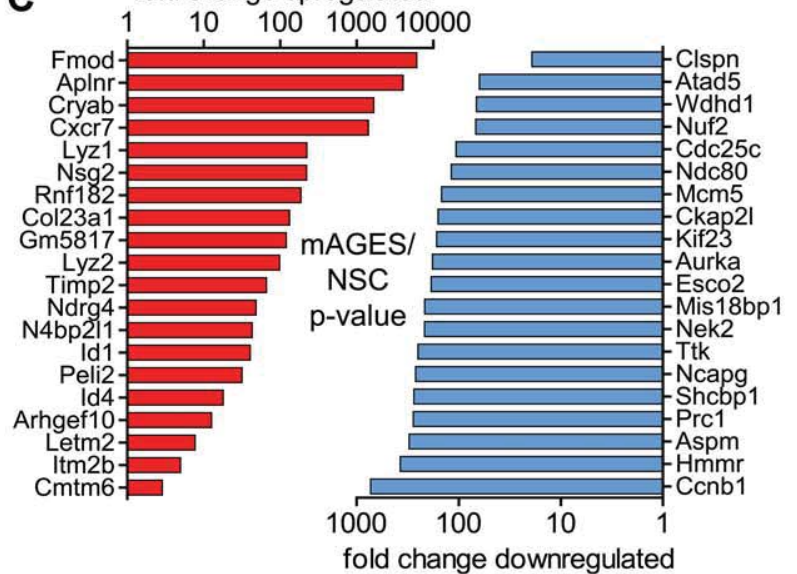

D fold change upregulated

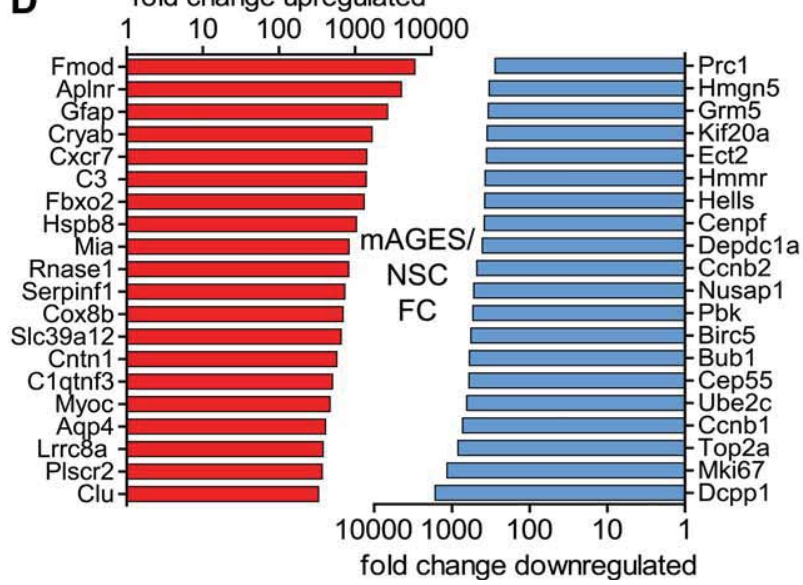

E
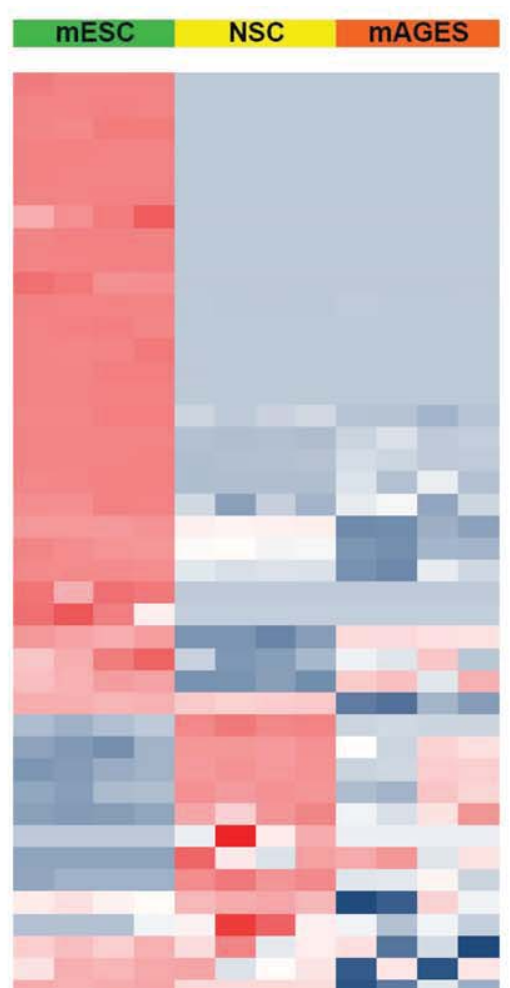

Tfcp $2 / 1$

Foxo15
Dppa2

Tdh

Fgf4

Dppa4

Zfp 42

Gjb3

Eras

ex19.1

Lefty2

Nanog

Tdgf1

Timp1

Msh2

Phf17

Lefty

Gab1

Sox 2
Cd9
$G$ d

Gn/3

Nes
Sox11

Tct4

Bmi1
Runx1

DCX

Cspg4

Lpar4

Meis1

Hes1 일

Ireb2 $=$

Nfe 212 ब

Cah2 2

Olig2 के

Pax6

Metrm

Notch1

Ascl1

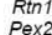

Nr2ff

Wnt5a

Olig1

Nedd9

Fofr2

Aqp 4

1 c39a 12

Mertk

Cyp $4 f 14$

Acta2 2

Ntsr2

Id 2
Fgfr 3

Ccdc80

Agt
Atp 1 a 2

Aldoc

Kcne1l

Ticd1

sc9azr1

Thrsp

Nfix

SIC25a18

Mic1

Soxg

Mgst1

Tho

Sparcl1

Sic1a3

Acsbg1

Ezr
Numb
Nate

Aldh1L1

Id 4
Gja1

Gja1
Glul

FIGURE 4: (Continued) 
glutamine source (Fig. 2). The measurement of label incorpora tion into the cellular glucose pool and glycolytic metabolites (3 phosphoglycerate, phosphoenolpyruvate) confirmed for both cell types the high glycolytic rate: the equilibrium state for label incorporation rates $(90 \%$ for glucose, $45 \%$ for the tricar bon metabolites) was reached within the first hour.

Analysis of the TCA cycle intermediate citrate showed a delayed equilibration of label incorporation at $1224 \mathrm{~h}$ (not shown), which is mainly due to a lower flux of glucose derived pyruvate entering the TCA cycle compared with the high glycolytic flux, but also due to the large pools of (unla beled) glutamate and aspartate in rapid exchange with TCA cycle intermediates. Still, the labeling of the citrate pool was faster and higher for NSC, suggesting differences in the metabolism of both cell populations (Fig. 6B). As citrate release is a well known peculiar property of astrocytes (West ergaard et al., 1994), we quantified the citrate release rate from mAGES and NSC by quantitative ${ }^{1} \mathrm{H}$ NMR spectros copy (Fig. 6C). NSC did not release significant amounts of citrate, while mAGES released citrate into the medium. A direct comparison with primary cortical astrocytes indicated that the overall range of their release rate is similar to the one of mAGES (albeit still somewhat higher) (Fig. 6C).

To investigate whether the observed differences in citrate release may have been due to medium conditions, we repeated experiments with mAGES in medium supplemented with $2 \mathrm{mM}$ glutamine. Under these conditions, citrate release was even enhanced, compared with glutamine free medium (used for the initial comparison). Conversely, NSC kept in glutamine free medium (instead of medium with $2 \mathrm{mM}$ gluta mine) did not show any citrate release (Supp. Info. Fig. S14). Thus, citrate release appears to be a unique cell intrinsic dif ference in metabolism between mAGES and NSC.

For further characterization of the net uptake or release of medium components, the amino acid content of the super natant was quantified $24 \mathrm{~h}$ after addition of fresh medium to the cells. NSC took up significant amounts of serine
(Fig. 6D), while mAGES did not affect the concentrations of this amino acid to a measurable extent. The same pattern was observed for all branched chain amino acids: leucine, isoleu cine (Fig. 6D), and valine were taken up by NSC, while mAGES did not contribute to a significant change in extrac ellular concentration. Net glutamate uptake was, however, more pronounced for mAGES than NSC.

The latter finding, based on long term net uptake, was investigated in more biochemical detail, since the glutamate glutamine shuttle between astrocytes and neurons plays an important role in brain physiology. Expression of glutamine synthetase and of the glutamate transporter GLAST by neural stem cells would in theory enable them to recycle glutamate, as in astrocytes, but this has not been tested directly. We eval uated therefore, as a first step, the glutamate uptake capacity by following the uptake of radiolabeled glutamate over a short period of time $(8 \mathrm{~min})$, and determining the initial speed for mAGES, NSC, and primary astrocytes. All cells transported the amino acid to a relatively similar extent (Fig. 7A).

To obtain a measure of cellular glutamine synthesis under steady state conditions, we studied incorporation of ${ }^{13} \mathrm{C}$ from $\mathrm{D}\left[1{ }^{13} \mathrm{C}\right]$ glucose into glutamine. The incorpora tion of parts of the glucose carbon skeleton into glutamine occurs via the citric acid cycle, $\alpha$ ketoglutarate formation, transamination of this metabolite to glutamate and finally the glutamine synthetase reaction (Fig. 7B). This biosynthetic pathway is competitive with i) the direct uptake of glutamine and ii) with the uptake of glutamate and use of this nonla beled metabolite in the glutamine synthethase reaction. Thus, the relative extent of label incorporation from glucose allows conclusions on the existence and competition of these three reactions in the test cell population. For glutamine free medium conditions (no glutamine uptake possible), we found that both NSC and mAGES synthesized glutamine (as indi cated by ${ }^{13} \mathrm{C}$ incorporation from glucose in about $20 \%$ of all glutamine). Thus, both cell types were capable of glutamine synthesis. When glutamine $(2 \mathrm{mM})$ was added to the

FIGURE 4: Transcriptome data of mESC, NSC, and mAGES and comparative analysis of gene expression to identify mature astrocyte marker genes. RNA was prepared from mESC, NSC, and mAGES ( 5 days old) in four independent experiments and used for Affymetrix Mouse Genome 4302.0 arrays. (A) To visualize the grouping patterns across different samples, a principal component analysis of global gene expression was performed for samples of 4 independent differentiations, and data (color coded) with their $95 \%$ confidence interval (gray shading) were plotted along the first two principal components (PC). (B) Gene expression datasets from (A) were used to compute differentially expressed genes (DEG) by applying the Empirical Bayes moderated $t$ statistics and adjusting for multiple hypothesis testing using the Benjamini Hochberg method. Genes with $\geq 2$ fold changes and an adjusted $P$ value $<0.05$ were considered as significant (with duplicates or nonannotated transcripts removed). The number of DEG is shown for different pairwise comparisons (e.g., mAGES vs. NSC) separately for upregulations (up, red) and downregulations (down, blue). (C) The gene list generated in (B) was sorted by adjusted $P$ value and the top 20 genes that were differentially expressed in mAGES relative to NSC are displayed. Bars indicate fold changes of genes, which were upregulated (red) or downregulated (blue). (D) The gene list generated in (B) was sorted by fold change and the top 20 DEG are presented. The adjusted $P$ value of all selected genes was $<10^{-5}$. (E) The gene expression values were retrieved for 94 genes selected from the literature as being specific for embryonic stem cells, neural stem cells, or astrocytes (listed vertically). The nor malized expression data on log scale obtained here (four times mESC, $4 \times \mathrm{NSC}, 4 \times \mathrm{mAGES}$ ) are plotted as horizontal lines of the heat map in the form of $z$ scores (blue color representing low and red color high expression). The corresponding gene expression values are listed in Supporting Information Fig. S11. [Color figure can be viewed in the online issue, which is available at wileyonlinelibrary.com.] 


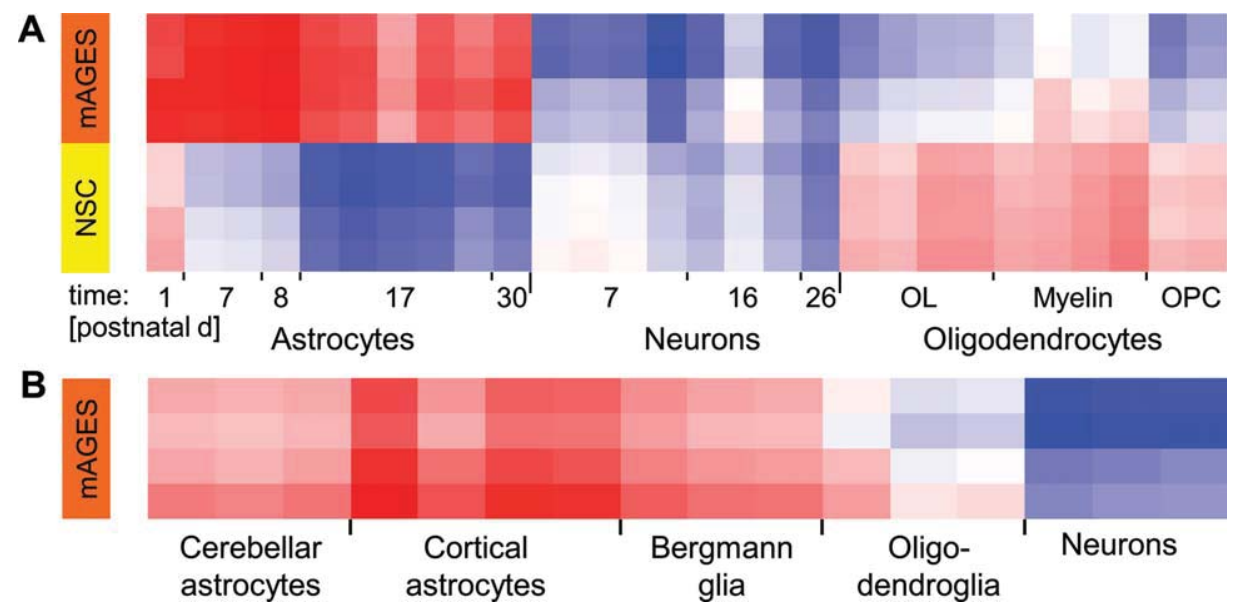

FIGURE 5: Correlation of mAGES microarray profiles with published data on astrocytes and other brain cell types. (A) The heatmap shows the Spearman correlation coefficient between NSC and mAGES (vertical axis) and data published by Cahoy et al. (2008) on pri mary astrocytes, neurons, or oligodendrocytes, isolated at different postnatal days (horizontal axis). (B) The heatmap shows the Spear man correlation coefficient between mAGES (vertical axis) and data from Doyle et al. (2008) on primary astrocytes from different brain regions, neurons, or oligodendrocytes (horizontal axis). The Spearman correlation was performed over the 94 selected genes (Fig. 4E). Blue color represents low correlation and red color high correlation (highest red value $=0.8$ in both cases). Samples are grouped by cell type across both studies; within the sample groups, the ordering was determined by a standard average linkage hierarchical clustering using the Euclidean distance metric. [Color figure can be viewed in the online issue, which is available at wileyonlinelibrary.com.]

medium, neither mAGES nor NSC produced significant amounts of glutamine from labeled glucose, i.e., direct gluta mine uptake was the dominating mechanism for filling the cellular glutamine pool (Fig. 7C). Thus, the cellular capacity of NSC (and mAGES) to synthesize glutamine (and the path way employed for it) depends on the overall metabolic situa tion. When we re examined the microarray data for hints of metabolic differences relevant to glutamate metabolism, we found that pyruvate carboxylase expression was 19 fold upreg ulated in mAGES compared with NSC. This enzyme cata lyzes the anaplerotic process of oxaloacetate formation from pyruvate to replenish $\alpha$ ketoglutarate in the TCA cycle, when this is used for glutamate and glutamine synthesis. In this context, pyruvate carboxylase has been reported to be astrocyte specific (Schousboe et al., 2013; Shank et al., 1985), as it allows a higher efficacy of glutamine synthesis from glu cose and TCA cycle metabolites in astrocytes.

As both NSC and mAGES were able to take up gluta mate and to synthesize glutamine, we were interested in their ability to release glutamine to the medium. The net release/ uptake was measured first in medium containing glutamine during a $24 \mathrm{~h}$ incubation period for the two cell types. Under these conditions, both mAGES and NSC showed a net con sumption of the amino acid of similar magnitude (Fig. 7D). By contrast, cell type differences became obvious in glutamine free medium: only mAGES released glutamine, whereas NSC did not release detectable amounts. Therefore, it appears that NSC cannot support the full glutamate glutamine recycling between astrocytes and neurons, and they therefore differ in this respect from astrocytes/mAGES.

\section{Functional Maturity of mAGES concerning Innate Immune Response and Neuronal Support}

We tested also directly, in how far mAGES were able to pro vide neuronal support. Human neurons, differentiated from the conditionally immortalized LUHMES cell line (Schild knecht et al., 2013; Scholz et al., 2011), were plated on top of mAGES. Within few days, stable co cultures formed and mAGES assumed an extreme star shaped morphology that is usually also observed for astrocytes present in primary rodent neuronal cultures (Supp. Info. Fig. S15A). When medium changes were stopped 2 days after plating the neurons, all LUHMES in monocultures died within 10 days, whereas vir tually all cells survived (and continued to do so for at least 4 weeks), when co cultured with mAGES (Supp. Info. Fig. S15B). Direct cell contact (of the somata) did not seem to be necessary for this effect, and a mAGES:LUHMES ratio as low as 1:5 seemed to be sufficient to support at least $80 \%$ neuronal survival (Supp. Info. Fig. S15C). NSC did not appear to support LUHMES neuron survival, although the data interpretation from such experiments is difficult due to differentiation processes in the NSC population during the culture period. Moreover, LUHMES cultured on mAGES had an increased synaptic density compared with LUHMES monocultures (Supp. Info. Fig. S16).

Besides metabolic functions pivotal for brain homeosta sis, important roles of astrocytes also involve their activation in inflammatory situations (Falsig et al., 2006, 2008), and neuronal support (Kuegler et al., 2012). Therefore, we exam ined here whether mAGES acquire similar properties, and in how far they differ from NSC. First, mAGES and NSC were 
A

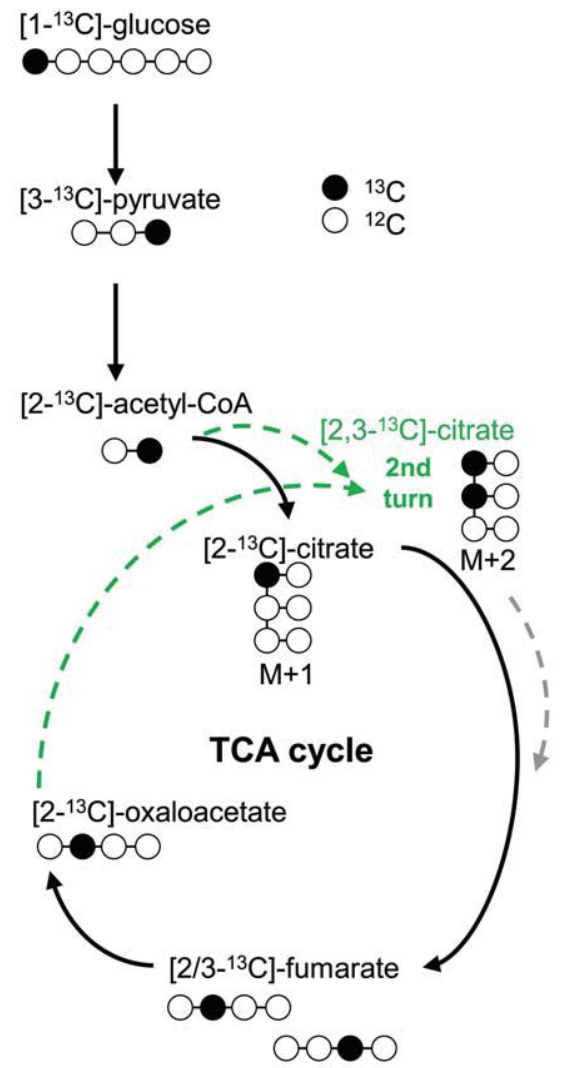

B

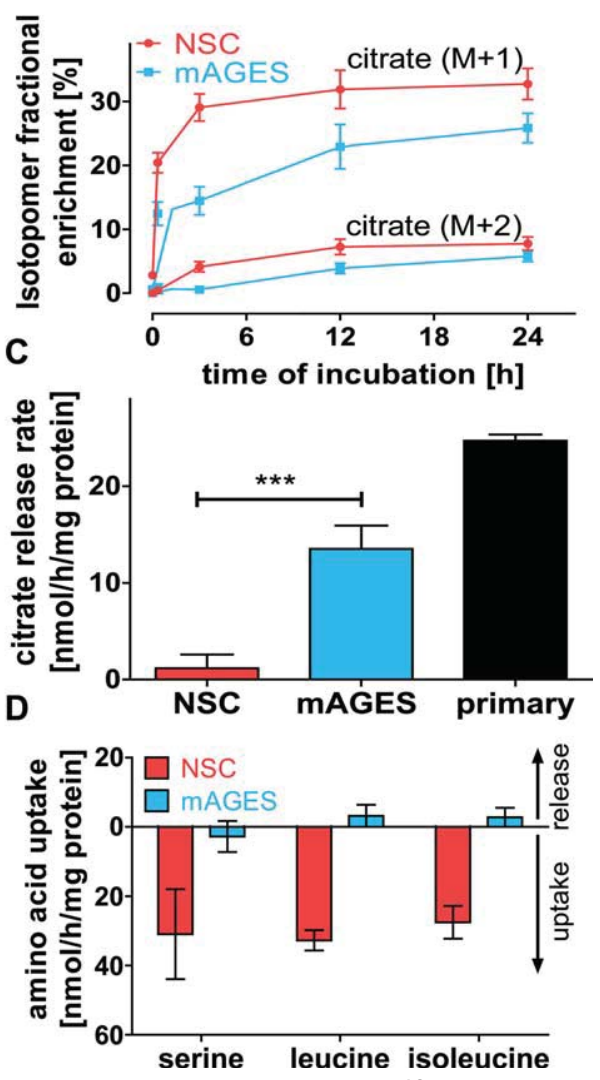

FIGURE 6: Differences in metabolic flux between NSC and mAGES. (A) Schematic representation of ${ }^{13} \mathrm{C}$ incorporation into citrate from D $\left[1{ }^{13} \mathrm{C}\right]$ glucose. The carbon skeleton of selected metabolites is shown. Citrate can incorporate ${ }^{13} \mathrm{C}$ at one carbon position (M+1), which is $\mathrm{C} 2$, from condensation of $\left[2{ }^{13} \mathrm{C}\right]$ acetyl $\mathrm{CoA}$ with unlabeled oxaloacetate. The $\mathrm{M}+2$ citrate isotopomer is generated, when $\left[2{ }^{13} \mathrm{C}\right]$ citrate is used in the tricarboxylic acid (TCA) cycle to generate $\left[2{ }^{13} \mathrm{C}\right]$ oxaloacetate, which condenses with $\left[2{ }^{13} \mathrm{C}\right]$ acetyl CoA, yielding double labeled $\left[2,3{ }^{13} \mathrm{C}\right]$ citrate. NB: Not shown here is that citrate might alternatively be labeled at $\mathrm{C} 4$ depending on label position in oxaloace tate at C3 (due to symmetric structure of fumarate). (B) Cells (mAGES/NSC) were plated in 6 well plates at a density of 500,000 cells/well for mAGES and 80,000 cells/well for NSC. After $48 \mathrm{~h}$ ( 5 days for mAGES), medium was changed to glucose free medium supplemented $10 \mathrm{mM} \mathrm{D}\left[1{ }^{13} \mathrm{C}\right]$ glucose. Supernatant as well as cell extracts were harvested at indicated time points. ${ }^{13} \mathrm{C}$ incorporation into citrate was measured in NSC and mAGES cell extracts after derivatization and analysis by gas chromatography mass spectrometry (GC MS). Iso topomer fractional enrichment above natural abundance of $1.2 \%$ (i.e., the percentage of the respective isotopomer of the total citrate pool) was measured for $\mathrm{M}+1$ (=citrate with one ${ }^{13} \mathrm{C}$ ), and $\mathrm{M}+2$ (=citrate with two ${ }^{13} \mathrm{C}$ atoms). (C) Experiments were performed as in (B) and citrate concentrations were measured in the supernatants of NSC and mAGES using ${ }^{1} \mathrm{H}$ NMR spectroscopy. For comparison, data from cortical astrocyte cultures were included. The overall protein content was measured in pellets of cell extracts, and the citrate release was normalized accordingly. (D) Experiments were performed as in (B) and serine, leucine, and isoleucine were measured in NSC and mAGES supernatants by HPLC. The overall protein content was measured in pellets of cell extracts, and amino acid uptake or release rates were calculated. All data are means \pm SEM from duplicate determinations in three independent experiments. ${ }^{* \star} P<0.001$ (One way ANOVA with Dunnett's post hoc test). [Color figure can be viewed in the online issue, which is available at wileyonlinelibrary.com.]

exposed to a mix of cytokines (complete cytokine mix (CCM): consisting of $10 \mathrm{ng} / \mathrm{mL} \mathrm{TNF} \alpha, 10 \mathrm{ng} / \mathrm{mL} \mathrm{IL} 1 \beta$, and $20 \mathrm{ng} / \mathrm{mL}$ IFN $\gamma$ ), which is normally found during brain inflammation, and is well established to activate the inflam matory master transcription factor NFkB in glial cells (Henn et al., 2011; Kuegler et al., 2012). CCM triggered pro nounced translocation of $\mathrm{NF \kappa B}$ from the cytosol to the nucleus in mAGES, but showed no effect at all in NSC (Fig. 8A, Supp. Info. Fig. S17). A more detailed investigation of the individual cytokines showed that translocation of NFKB was induced by TNF $\alpha$ as well as IL $1 \beta$, but not by IFN $\gamma$ (Fig. 8B). This activation pattern was similar to the one found before in primary astrocytes (Falsig et al., 2004; Henn et al., 2011), and in mAGES from different mESC and iPSC lines (Supp. Info. Fig. S6).

Translocation of NFKB is an inflammation event easily quantifiable on single cell level, and indicating cytokine receptor activation. To obtain information on the actual inflammatory activation, it is necessary to measure relevant mRNA levels directly. Indeed, we found that CCM induced the expression of the cytokine $I L-6$, the inducible nitric oxide synthase Nos-2, and the toll like receptor Tlr-2 (Fig. 8C). All three exemplary marker genes used here, were upregulated in mAGES at $4 \mathrm{~h}$ after incubation with CCM at least 100 fold. 
A

C

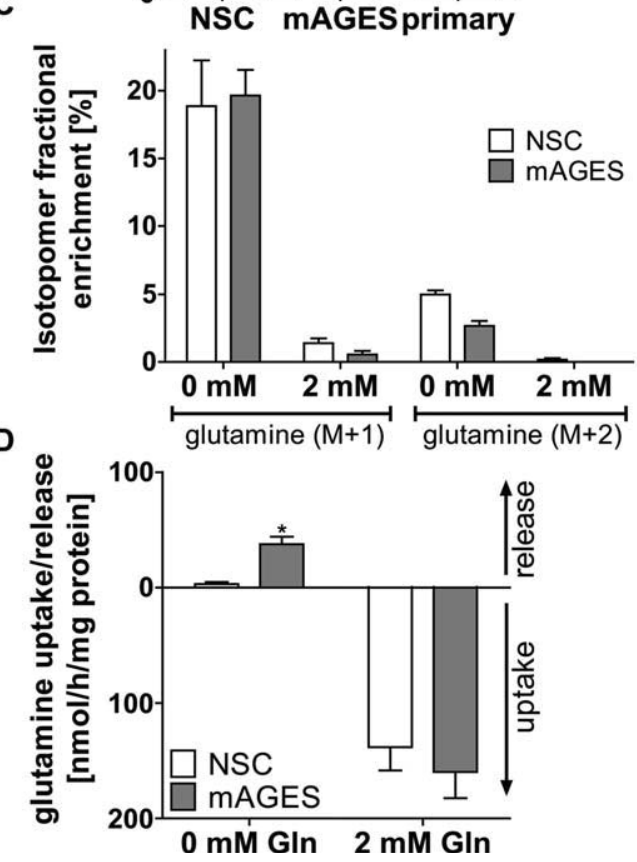

B

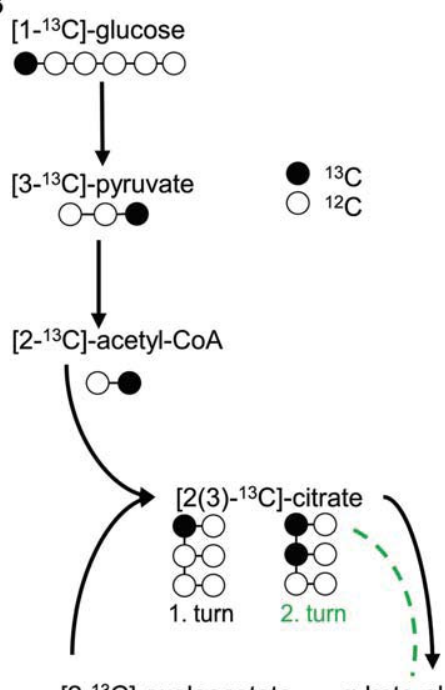

[2-13 C]-oxaloacetate $\alpha$-keto-glutarate

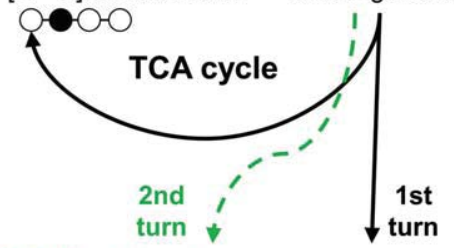

[3,4-13C]-glutamate

[4-13C]-glutamate

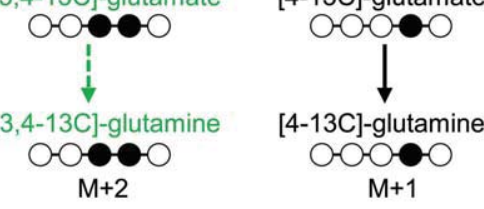

FIGURE 7: Similarities and differences of NSC and mAGES concerning metabolic processes related to the glutamate glutamine cycle. (A) NSC, mAGES (5 days old), and primary astrocytes were incubated with glutamate $\left(10 \mu \mathrm{M}\right.$, radiolabeled $\left({ }^{3} \mathrm{H}\right)$ with $0.12 \mu \mathrm{Ci} /$ well) in PBS for 8 minutes. After 3 rapid washing steps with PBS, cells were lysed and the cellular glutamate content was measured using a scintilla tion counter. The uptake data were normalized to mAGES as $100 \%$ reference point. (B) Schematic representation of ${ }^{13} \mathrm{C}$ incorporation into glutamate and glutamine from $D\left[1{ }^{13} \mathrm{C}\right]$ glucose: the carbon skeleton of selected metabolites is shown. Direct metabolism of glu cose to pyruvate \&cenveo unknown entity wingdings FOEO; acetyl CoA \&cenveo unknown entity wingdings FOEO; citrate \&cenveo unknown entity wingdings FOEO; $\alpha$ keto glutarate can lead to the formation of glutamine with one ${ }^{13} \mathrm{C}$ atom incorporated at positon $\mathrm{C} 4(\mathrm{M}+1)$. Use of the already singly labeled tricarboxylic acid (TCA) cycle metabolite [2 ${ }^{13} \mathrm{C}$ ] oxaloacetate in the citrate synthase reaction can lead to the formation of double labeled $\left[2,3{ }^{13} \mathrm{C}\right.$ ] citrate. This can then be further metabolized to double labeled $\alpha$ keto glutarate, $\left[3,4{ }^{13} \mathrm{C}\right]$ glutamate and $\left[3,4{ }^{13} \mathrm{C}\right]$ glutamine $(\mathrm{M}+2)$. (C) Cells (mAGES/NSC) were plated in six well plates at a density of 500,000 cells/well for mAGES and 80,000 cells/well for NSC. After 48 h (5 days for mAGES), medium was changed to glucose free medium supplemented with $10 \mathrm{mM} \mathrm{D}\left[1^{13} \mathrm{C}\right]$ glucose with either $2 \mathrm{mM}$ glutamine (Gln) or no Gln. Supernatants and cell extracts were harvested at $0.3,3,12$, and $24 \mathrm{~h}$. 13C incorporation into glutamine was measured by gas chromatography mass spectrometry (GC MS) in NSC and mAGES cell extracts. Isotopomer fractional enrichment (i.e., the percentage of the respective isotopomer of the total gluta mine pool) was measured over time for $M+1$ (=glutamine with one ${ }^{13} \mathrm{C}$ ), and $\mathrm{M}+2$ (=glutamine with two ${ }^{13} \mathrm{C}$ atoms). It is displayed here for the $12 \mathrm{~h}$ incubation (=steady state level). (D) Experiments were performed as in (C) and supernatants were harvested at $12 \mathrm{~h}$. Glutamine concentrations were measured by HPLC. The overall protein content was measured in pellets of cell extracts, and the uptake or release rate were calculated (similar results were obtained at $24 \mathrm{~h}$ ). All data are means \pm SEMs from three independent experiments, ${ }^{\star} P<0.01$ (One way ANOVA with Dunnett's post hoc test). [Color figure can be viewed in the online issue, which is available at wileyonli nelibrary.com.]

NSC did not upregulate any of the genes when exposed to CCM (data not shown). For data on an actual functional response to inflammatory stimulation, we chose to measure IL 6 secretion by ELISA. Again, TNF $\alpha$ as well as IL $1 \beta$, but not IFN $\gamma$, induced the production and the release of IL 6 . On the level of protein secretion, there was an additive effect of the cytokines (Fig. 8D), exactly as described for primary astrocytes earlier (Falsig et al., 2004; Henn et al., 2011).
NSC did not release any IL 6 when exposed to CCM (not shown). In summary, mAGES, but not NSC, responded to inflammatory cytokines, and the response pattern was consist ent with that of primary astrocytes.

\section{Discussion}

The study of metabolic and functional features of astrocytes, in their resting state or in different defined activation 
scenarios, faces a number of challenges: (i) measurements in vivo require a distinction of astrocytes from surrounding cells for the analytical endpoints chosen; (ii) ex vivo studies, using, e.g., FACS purified adult astrocytes, suffer from a compro mised viability of the obtained cells, and from undefined acti vation states, when put in culture; (iii) in vitro studies mainly rely on studies of mixed populations, prepared from relatively immature cells. They may contain precursor cells, reactive astrocytes and other cell types, such as microglia. Additional approaches would thus be desirable to further explore astro cyte biology. In this study, we present such an alternative strategy that allows generation of a pure population of non proliferative, nonactivated astrocytes suitable for functional studies (neuronal support, inflammatory activation), investiga tion of metabolism (metabolite exchange, metabolic flux), and direct comparison to their immediate precursors, i.e., neural stem cells (NSC). The simultaneous availability of NSC, and of a population of nonproliferating astrocytes (mAGES) derived directly therefrom allowed us a direct com parison of the two cell types, and the identification of differ ences and similarities on the level of gene expression and intermediary metabolism (Fig. 9).

The heterogeneity of astrocytes derived from rodent brains or from stem cells has been underestimated in the past, as it has been common in the field to strongly rely on few sin gle markers, such as GFAP. Nowadays, it is well described that there exist a subpopulation of mature GFAP negative astrocytes, which express astrocyte marker genes apart from GFAP and reveal functional inflammatory capacity (Cahoy et al., 2008; Kuegler et al., 2012; Pekny et al., 1995; Walz and Lang, 1998). For many studies, a quantification of negative markers indica tive of contaminating or immature cells is often missing. It is clear now that a single marker cannot define the cells (Gotz et al., 2015), and that functional properties (e.g., cell cycle pro gression, glutamate conversion or response to cytokines) need to be combined with an extensive set of markers. For instance, we found that GFAP positive cells may co express nestin or not, and also be proliferative or not, depending on the culture conditions. Such observation by us and others are in good agreement with findings that astrocytes generated from NSC by LIF, CNTF or FBS all expressed GFAP, but otherwise strongly differed from one another (Brunet et al., 2010). Here we found that the most complete conversion to nondividing astrocytes occurred in the presence of BMP4, while addition of serum (FBS), which is frequently used in other protocols, exposes the cells to an undefined mixture of growth factors, some of which (e.g., EGF) also stimulate proliferation. The inevitable use of FBS in conventional primary astrocyte cultures might therefore explain the heterogeneity of developmental stages in such cul tures. Moreover many studies are not truly based on primary cells, but rather secondary or tertiary cultures. The associated selection and expansion of subpopulations, and cell activation may be the reason for contradictory studies on astrocytic inflammatory functions and makes it impossible to attribute specific metabolic functions unambiguously to primary mature astrocytes.

The absence of immature or reactivated cells in our cul tures was indicated by the very strong downregulation of nes tin as well as markers of immature astrocytes (A2B5, CD44). The maturity of mAGES was further confirmed by a cell cycle arrest (which persisted over weeks) in all cells in mAGES cultures. Moreover, we exclude the generation of quiescent stem cells, which may occur in some biological con text as a consequence of the addition of BMP4 (Andreu et al., 2015; Martynoga et al., 2013; Mira et al., 2010): The quiescent stem cell marker CD133/prominin1 was not expressed in mAGES (Supp. Info. Fig. S18) and the cells did not re enter the cell cycle when exposed to EGF or sonic hedgehog $(\mathrm{SHH})$ within 10 days of exposure, as it would be expected from quiescent stem cells (Codega et al., 2014). As the procedure we describe here was reproducible for several lines of ESC or for iPSC, and as large numbers of cells can be produced by this protocol in a fast and cost efficient way, mAGES are suggested here as valuable additional model sys tem to study the cell biology (e.g., epigenetics, metabolic adaptation, inflammation, gene regulation, or cell cycle re activation) of astrocytes. Generation of mAGES from BTBR ESC, i.e., from a mouse strain used for autism studies (McFarlane et al., 2008), shows that the protocol is suitable also for the study of genetic modifications underlying disease.

For the study of human genes contributing to disease, it would be desirable to transfer the protocol to human cells. At the present stage, we cannot predict whether this will be possi ble with the same speed and efficiency as found in the murine system. The key factor for the efficient and rapid differentia tion of mAGES was the generation of the right type of precur sors. To our knowledge, the human equivalent has not yet been found, despite large efforts. Several protocols to generate astrocytes from human ESC or iPSC have been published (Gupta et al., 2012; Juopperi et al., 2012; Krencik et al., 2011; Sun et al., 2008). They often require excessively long differen tiation times ( $>3$ months), and the obtained cell populations usually contain substantial amounts of precursors or other cell types. For instance, a recent, very efficient protocol developed by experienced specialists in the field generated purities of 70 $80 \%$ at best (Shaltouki et al., 2013). Such cells have been used successfully for transcriptome profiling, but long term studies and investigations in metabolic pathways might be compli cated by other cells present. Even cells offered commercially from the best known source for stem cell derived products (Cellular Dynamics iCell astrocytes; www.cellulardynamics. $\mathrm{com} /$ products/astrocytes.html) are very strongly proliferative. 

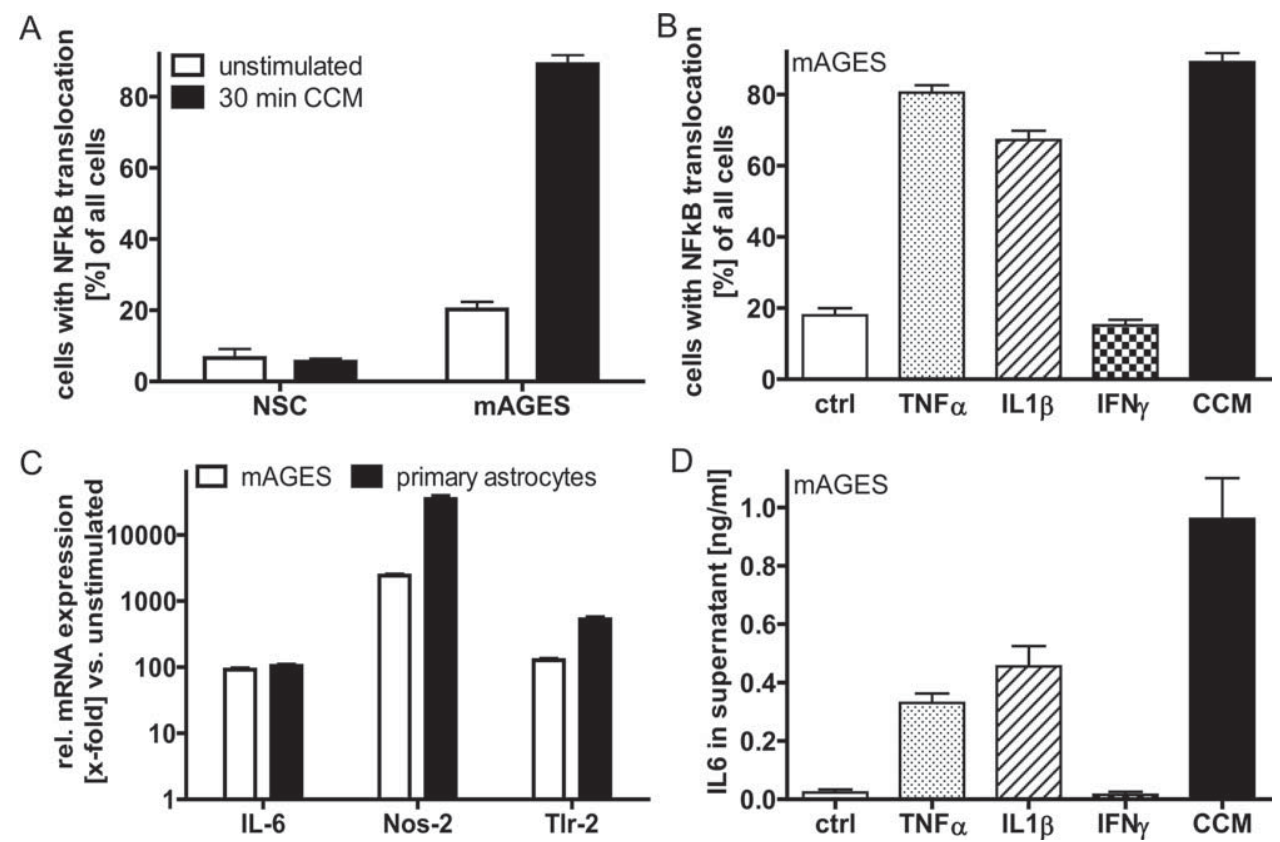

FIGURE 8: Response of mAGES, but not NSC, to inflammatory stimulation. (A) NSC and 5 days old mAGES were exposed to complete cytokine mix (CCM, $10 \mathrm{ng} / \mathrm{mL} \mathrm{TNF} \alpha, 10 \mathrm{ng} / \mathrm{mL}$ IL $1 \beta$, and $20 \mathrm{ng} / \mathrm{mL}$ IFN $\gamma$ ) for $30 \mathrm{~min}$. Then, cells were fixed, permeabilized, and immuno stained for the p65 unit of the inflammatory transcription factor NF кB (NFkB). Nuclei were counterstained with $H 33342$. The ratio of NFkB in the cytosol and the nucleus was measured in NSC and mAGES cultures by an automated screening microscope $(1,000$ nuclei/ condition) and an image data processing procedure based on a validated algorithm. The percentage of cells with NFkB translocation into the nuclei was calculated and presented. See Supporting Information Fig. S17 for representative images. (B) NFkB translocation was determined as in (A) for mAGES exposed to CCM or its single components for $30 \mathrm{~min}$. (C) Primary astrocytes and mAGES were stimulated with CCM, and mRNA was isolated $4 \mathrm{~h}$ later from control and stimulated cells. The expression of three inflammatory markers (IL 6; inducible nitric oxide synthase (iNOS); toll like receptor 2 (TLR2) was analyzed by qPCR. Data are given for CCM exposed cells rela tive to the expression in unstimulated control cells. (D) mAGES were exposed to CCM for $8 \mathrm{~h}$. Supernatants were harvested, and IL 6 protein was measured by ELISA. All data are means \pm SEMs from three independent experiments.

A recent advance may be the generation of "late radial glia cells" as precursor population. This protocol allowed then the generation of up to $88 \%$ GFAP positive cells within 7 days of the addition of BMP4 (Duan et al., 2015). Although this latter procedure, close to the one presented here for mAGES, sounds promising, there are some issues that need to be resolved: the generation of the right precursors takes over 100 days; it is not yet clear, whether these precursor cells have sufficient prolifera tive and self renewal capacity to allow astrocyte generation at a reasonable cost; and it is not clear whether the astrocytes gen erated show the required functional features and are nondivid ing. An exact definition of the required precursor cell population in the mouse system may help to guide protocol optimization for human cells. To obtain the required data, it may be helpful to compare the transcript profile of NSC of the present study to NSC we have used earlier for the genera tion of mESC derived astrocytes (MEDA). The latter protocol (Kuegler et al., 2012) generated astrocyte cultures with a large proportion of mature astrocytes, but also with subpopulations of immature cells and rapidly dividing cells (i.e., similar to the situation usually observed in the currently available human stem cell derived astrocytes). A better selection of the precur sors by repeated selective passaging of the desired subpopula tion, made all the difference in the speed, efficacy and homogeneity of the mAGES generation. Thus, knowledge of differentially expressed genes or surface markers for the desired start population is expected to accelerate such a process for human cells. We hope that the detailed description of the piv otal protocol steps of mAGES generation not only helps the implementation of mAGES in the research community, but would also support the optimization of protocols for human astrocytes.

The availability of mAGES and NSC in highly homoge neous cultures allowed comparisons of their metabolic charac teristics. Earlier studies found expression of glutamate transporters as well as the glutamine synthetase in both cell types. The functionality of NSC glutamate transporters was then shown in short term biochemical D aspartate uptake experiments (Brunet et al., 2004). Our cultures provided now an experimental basis for steady state studies (as part of cellular homeostasis) on the role of glutamate uptake/glutamine release during prolonged culture times. This allowed conclusions on the role that NSC may take part in glutamate glutamine recy cling. The finding that both NSC and mAGES were able to take up glutamate and convert it to glutamine suggests that neural stem cells resemble astrocytes in this metabolic function. 


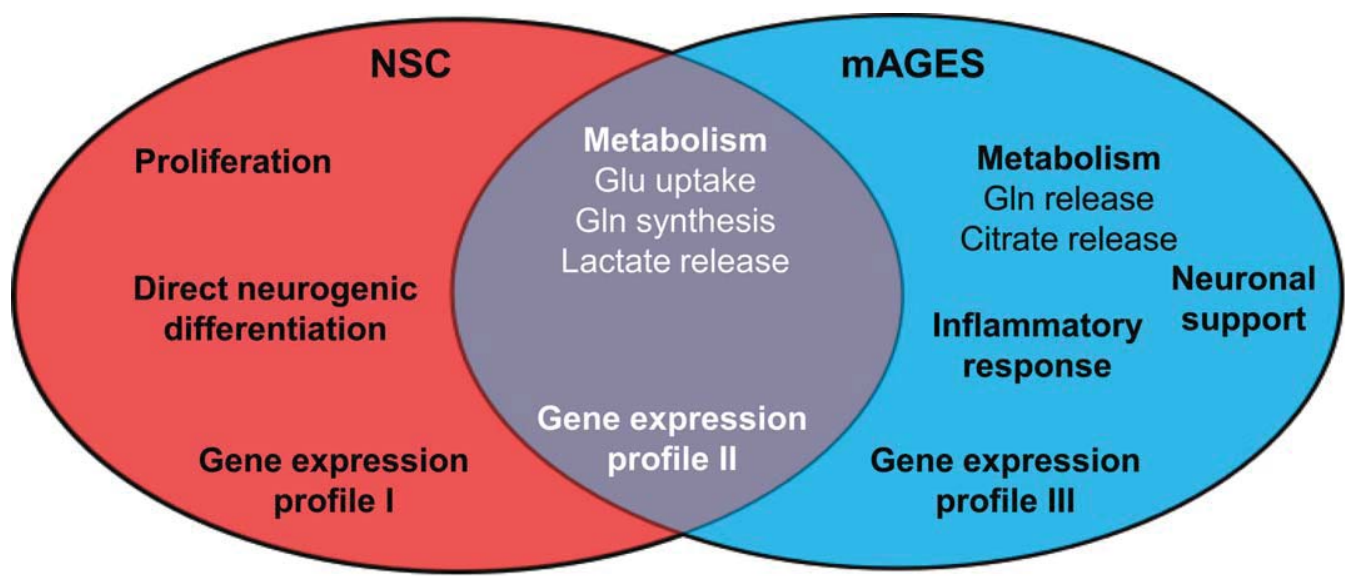

\begin{tabular}{|c|c|c|c|c|c|c|c|c|c|}
\hline \multicolumn{10}{|c|}{ Gene expression profile } \\
\hline \multicolumn{2}{|c|}{1} & \multirow{2}{*}{\multicolumn{4}{|c|}{$\begin{array}{c}\text { II } \\
\text { overlap, } \\
\text { not specific }\end{array}$}} & \multicolumn{4}{|c|}{ III } \\
\hline \multirow{2}{*}{$\begin{array}{c}\begin{array}{c}\text { confirmed } \\
\text { (diff. }>1.8)\end{array} \\
\text { Nes }\end{array}$} & $\begin{array}{l}\text { new and } \\
\text { validated }\end{array}$ & & & & & \multicolumn{2}{|c|}{$\begin{array}{r}\text { confirmed } \\
(\text { diff. }>1.8)\end{array}$} & \multicolumn{2}{|c|}{$\begin{array}{l}\text { new and } \\
\text { validated }\end{array}$} \\
\hline & Ccnb1 & Sox11 & Pax6 & Tlcd1 & Acsbg1 & Gfap & Ccdc80 & Fmod & Nedd9* \\
\hline Bmi1 & $\mathrm{Hmmr}$ & Tcf 4 & Metrn & Slc9a3r1 & Ezr & Aqp4 & Agt & Aplnr & Fgfr2* \\
\hline Egfr & Aspm & Runx1 & Notch1 & s100b & Numb & Slc39a12 & Aldoc & Cryab & \\
\hline Ireb2 & Gja1* & Lpar4 & Ascl1 & Slc25a18 & Glul & Mertk & Kcne1I & Cxcr7 & \\
\hline Fabp7 & & Meis1 & Rtn1 & Csad & & Cyp4f14 & Pbxip1 & Lyz1/2 & \\
\hline \multirow[t]{5}{*}{ Olig2 } & & Hes1 & Pex2 & Sox 9 & & Pygb & Thrsp & Nsg2 & \\
\hline & & DII3 & $N r 2 f 1$ & Mgst1 & & Acta2 & Nfix & Rnf182 & \\
\hline & & $\mathrm{Nfe} 2 / 2$ & Wnt5a & Tnc & & Ntsr2 & Mlc1 & Col23a1 & \\
\hline & & Hes6 & Olig1 & Sparcl1 & & Id2 & Aldh1L1 & Timp2 & \\
\hline & & Cdh2 & Atp1a2 & Slc1a3 & & Fgfr3 & Id 4 & Ndrg4 & \\
\hline
\end{tabular}

FIGURE 9: Summary of differences and similarities between NSC and mAGES. NSC (blue) and mAGES (red) show functional differences as well as similarities (intersection, purple). Gene expression profiles based on microarray profiling are listed below. The specific marker genes suggested below are (i) known NSC or astrocyte markers (see Fig. 4E); (ii) had a logarithmic mean expression value higher than 4 in one of the cell types (to avoid genes with borderline expression); (iii) and showed a difference in their logarithmic mean expression values (mAGES vs. NSC) higher than 1.8 (3.48 fold difference). "New genes" comprise the top DEG between NSC and mAGES, which were validated by qPCR. *: genes labelled with asterisk were found here to show expression differences of 3.5 fold between mAGES and NSC, but they have previously been discussed as potential markers for the other cell type than the one listed here (i.e., their specifi cation was revised by our study). [Color figure can be viewed in the online issue, which is available at wileyonlinelibrary.com.]

However, NSC did not release glutamine to the extracellular space as mAGES did. Thus, NSC are probably not involved in the glutamate glutamine shuttle between astrocytes and neu rons. However, glutamine synthetase activity is also essential for detoxification of excessive ammonia in the brain. NSC may take part in this important process.

A further metabolic difference of mAGES and NSC concerned the release of citrate to the extracellular space. This peculiar metabolic feature has been known for astrocytes (Westergaard et al., 1994), and was now confirmed for the highly homogeneous mAGES cultures, while this process was not detected in NSC. Furthermore, NSC clearly differed from mAGES by their net exchange pattern for various amino acids. The interpretation of such metabolic studies requires homogeneous populations to exclude subpopulations responsible for altered overall metabolite patterns. The data generated here suggest that the cultures are suitable for more extensive mapping of overall cellular metabolic fluxes, and for the comparison of such data to primary astrocyte cultures (Amaral et al., 2011) and other cell types.

In the fields of immunology and stem cell biology, it has long become a rule that cells cannot be characterized by single markers, but rather by signatures across multiple positive and negative markers. The recognition of astrocyte heterogeneity has now led to a critical reexamination of the specificity of established marker genes in the field of neurosciences. Microar ray studies provide new insight in corresponding multifactorial marker patterns of glial cells (Beckervordersandforth et al., 2010; Gotz et al., 2015). Classical single markers, such as GFAP, may still play a role in the distinction of neurons or microglia from astrocytes, but multiple markers and full expres sion profiles are required to characterize closely related cell pop ulations. This is the case for a comparison between astrocytes and their self renewing precursors, as presented here. The gene expression data generated in this study can be used to define a predictive set of differentially expressed genes for in vitro 
differentiation experiments in different settings. Such marker selection benefits largely from earlier gene expression studies of different murine cell populations that helped to define com monalities and differences of astrocytes from different brain regions, developmental stages and activation states (Beckervor dersandforth et al., 2010; Buffo et al., 2008; Cahoy et al., 2008; Dimou and Gotz, 2014; Lovatt et al., 2007). In vitro, such studies have in the past been mainly used to define cell activation states (Falsig et al., 2006; John et al., 2005), while less information is available on the ground state of murine astrocytes cultures as opposed to other cell types. Here, we used microarray analysis to explore differentially expressed genes between NSC, mAGES and pluripotent ESC similarly to what has been done for human cells (Shaltouki et al., 2013). More over, the data were used for comparisons to some available data sets on astrocytes. As our system provides the opportunity to directly compare mAGES to their immature precursors, new RNA markers of mature cells such as fibromodulin (Fmod) could be readily identified (Fig. 9). The cognate protein (fibro modulin) is involved in extracellular matrix organization, which is one of the first recognized and accepted functions of astro cytes that has been described in connection with astrocytes functioning as "brain glue" (Volterra and Meldolesi, 2005).

Since differentiation of mAGES is very fast, and all steps are easily accessible at every stage, it offers the possibility to investigate factors and, e.g., toxicants or drugs that disturb astrocyte generation. For instance, valproic acid (VPA) has been shown to disturb astrocyte generation, while it favors neurogenesis (Su et al., 2014). We confirmed this property in a study that examined the generation of mAGES with read outs of maturity markers on the single cell level. Our system can thus be used for high throughput screenings of develop mental toxicants, or for general studies of astrocyte develop ment, for instance with regard to gene regulation, acquisition of immune functions and of biological features controlling the expression of cytokine receptors.

The differentiation of mAGES from different iPSC lines offers new possibilities to investigate the involvement of astro cytes in processes leading to disease establishment or progres sion. Such approaches have already been taken with astrocyte enriched cultures derived from human iPSC with a Hunting ton's disease genetic background (Juopperi et al., 2012), or a Rett syndrome genotype (Lioy et al., 2011). The availability of a wealth of transgenic and gene targeted mice, or the possi bility of direct manipulation of NSC or mAGES offers multi ple opportunities for the study of disease related genes. Besides such studies, the inflammation competence of mAGES might be utilized to study the causes and consequences of astrocyte activation in multiple neurological diseases. More over, the easy availability of the cells, and their compatibility with, e.g., human neuronal cultures allows also investigations of neuroprotective or neurodamaging roles of astrocytes (Efre mova et al., 2015; Schildknecht et al., 2015).

In summary, our exact characterization of the differentia tion requirements, together with data on the phenotype and function of the resultant cells, suggests that generation of astro cytes from pluripotent stem cells (mAGES) is a viable alterna tive to the preparation of primary astrocytes for biological, pharmacological and toxicological studies. The direct compari son of mAGES and NSC performed here provided new insights into astrocyte and neural stem cell metabolism. In the future, the generation of mAGES with different genetic back grounds opens up new possibilities in biomedical research.

\section{Acknowledgment}

Embryonic stem cell lines BTBR $T^{+} I_{t p r} 3^{t f} \mathrm{~J}$ PB60.6 and DO335.45 were kindly provided by Predictive Biology, Carls bad, CA, USA.

\section{References}

Amaral Al, Teixeira AP, Martens S, Bernal V, Sousa MF, Alves PM. 2010. Metabolic alterations induced by ischemia in primary cultures of astrocytes: merging 13C NMR spectroscopy and metabolic flux analysis. J Neurochem 113:735-748.

Amaral Al, Teixeira AP, Hakonsen BI, Sonnewald U, Alves PM. 2011. A comprehensive metabolic profile of cultured astrocytes using isotopic transient metabolic flux analysis and C-labeled glucose. Front Neuroenergetics 3:5.

Andreu Z, Khan MA, Gonzalez-Gomez P, Negueruela S, Hortiguela R, San Emeterio J, Ferron SR, Martinez G, Vidal A, Farinas I, Lie DC, Mira H. 2015. The cyclin-dependent kinase inhibitor p27 kip1 regulates radial stem cell quiescence and neurogenesis in the adult hippocampus. Stem Cells 33:219-229.

Bayraktar OA, Fuentealba LC, Alvarez-Buylla A, Rowitch DH. 2015. Astrocyte development and heterogeneity. Cold Spring Harb Perspect Biol 7:a020362.

Beckervordersandforth R, Tripathi P, Ninkovic J, Bayam E, Lepier A, Stempfhuber B, Kirchhoff F, Hirrlinger J, Haslinger A, Lie DC, Beckers J, Yoder B, Irmler M, Gotz M. 2010. In vivo fate mapping and expression analysis reveals molecular hallmarks of prospectively isolated adult neural stem cells. Cell Stem Cell 7:744-758.

Benjamini Y, Hochberg Y. 1995. Controlling the false discovery rate: A practical and powerful approach to multiple testing. J R Stat Soc Ser B (Methodological) 289-300.

Brunet JF, Allaman I, Magistretti PJ, Pellerin L. 2010. Glycogen metabolism as a marker of astrocyte differentiation. J Cereb Blood Flow Metab 30:51-55.

Brunet JF, Grollimund L, Chatton JY, Lengacher S, Magistretti PJ, Villemure JG, Pellerin L. 2004. Early acquisition of typical metabolic features upon differentiation of mouse neural stem cells into astrocytes. Glia 46:8-17.

Buffo A, Rite I, Tripathi P, Lepier A, Colak D, Horn AP, Mori T, Gotz M. 2008. Origin and progeny of reactive gliosis: A source of multipotent cells in the injured brain. Proc Natl Acad Sci U S A 105:3581-3586.

Cahoy JD, Emery B, Kaushal A, Foo LC, Zamanian JL, Christopherson KS, Xing Y, Lubischer JL, Krieg PA, Krupenko SA, Thompson WJ, Barres BA. 2008. A transcriptome database for astrocytes, neurons, and oligodendrocytes: A new resource for understanding brain development and function. J Neurosci 28:264-278.

Candelario KM, Shuttleworth CW, Cunningham LA. 2013. Neural stem/progenitor cells display a low requirement for oxidative metabolism independent of hypoxia inducible factor-1alpha expression. J Neurochem 125:420-429. 
Codega P, Silva-Vargas V, Paul A, Maldonado-Soto AR, Deleo AM, Pastrana E, Doetsch F. 2014. Prospective identification and purification of quiescent adult neural stem cells from their in vivo niche. Neuron 82:545-559.

Conti L, Pollard SM, Gorba T, Reitano E, Toselli M, Biella G, Sun Y, Sanzone S, Ying QL, Cattaneo E, Smith A. 2005. Niche-independent symmetrical selfrenewal of a mammalian tissue stem cell. PLoS Biol 3:e283.

Crocker SJ, Frausto RF, Whitton JL, Milner R. 2008. A novel method to establish microglia-free astrocyte cultures: Comparison of matrix metalloproteinase expression profiles in pure cultures of astrocytes and microglia. Glia 56:1187-1198.

Daikhin Y, Yudkoff M. 2000. Compartmentation of brain glutamate metabolism in neurons and glia. J Nutr 130:1026S-1031S

Delaney $\mathrm{CL}$, Brenner M, Messing A. 1996. Conditional ablation of cerebellar astrocytes in postnatal transgenic mice. J Neurosci 16:6908-6918.

Dimou L, Gotz M. 2014. Glial cells as progenitors and stem cells: New roles in the healthy and diseased brain. Physiol Rev 94:709-737

Doetsch F, Caille I, Lim DA, Garcia-Verdugo JM, Alvarez-Buylla A. 1999. Subventricular zone astrocytes are neural stem cells in the adult mammalian brain. Cell 97:703-716

Doyle JP, Dougherty JD, Heiman M, Schmidt EF, Stevens TR, Ma G, Bupp S, Shrestha P, Shah RD, Doughty ML, Gong S, Greengard P, Heintz N. 2008 Application of a translational profiling approach for the comparative analysis of CNS cell types. Cell 135:749-762.

Duan L, Peng CY, Pan L, Kessler JA. 2015. Human pluripotent stem cellderived radial glia recapitulate developmental events and provide real-time access to cortical neurons and astrocytes. Stem Cells Transl Med 4:437-447.

Efremova L, Schildknecht S, Adam M, Pape R, Gutbier S, Hanf B, Burkle A, Leist M. 2015. Prevention of the degeneration of human dopaminergic neurons in an astrocyte co-culture system allowing endogenous drug metabolism. Br J Pharmacol 172:4119-4132.

Eng LF, Ghirnikar RS, Lee YL. 2000. Glial fibrillary acidic protein: GFAP-thirtyone years (1969-2000). Neurochem Res 25:1439-1451.

Falsig J, Latta M, Leist M. 2004. Defined inflammatory states in astrocyte cultures: Correlation with susceptibility towards CD95-driven apoptosis J Neurochem 88:181-193.

Falsig J, Porzgen P, Lund S, Schrattenholz A, Leist M. 2006. The inflammatory transcriptome of reactive murine astrocytes and implications for their innate immune function. J Neurochem 96:893-907

Falsig J, van Beek J, Hermann C, Leist M. 2008. Molecular basis for detection of invading pathogens in the brain. J Neurosci Res 86:1434-1447.

Gotz M, Sirko S, Beckers J, Irmler M. 2015. Reactive astrocytes as neural stem or progenitor cells: In vivo lineage, in vitro potential, and genome-wide expression analysis. Glia 63:1452-1468.

Gupta K, Patani R, Baxter P, Serio A, Story D, Tsujita T, Hayes JD, Pedersen RA, Hardingham GE, Chandran S. 2012. Human embryonic stem cell derived astrocytes mediate non-cell-autonomous neuroprotection through endogenous and drug-induced mechanisms. Cell Death Differ 19:779-787.

Hansson E. 1986. Primary astroglial cultures. A biochemical and functional evaluation. Neurochem Res 11:759-767.

Henn A, Kirner S, Leist M. 2011. TLR2 hypersensitivity of astrocytes as functional consequence of previous inflammatory episodes. J Immunol 186:3237-3247.

Hernández C, Martín M, Bodega G, Suárez I, Pérez J, Fernández B. 1999 Response of carp central nervous system to hyperammonemic conditions: An immunocytochemical study of glutamine synthetase (GS), glial fibrillary acidic protein (GFAP) and $70 \mathrm{kDa}$ heat-shock protein (HSP70). Aquat Toxicol 45 195-207

Ihaka R, Gentleman R. 1996. R: A language for data analysis and graphics. J Comput Graph Statistics 5:299-314

Ihrie RA, Alvarez-Buylla A. 2008. Cells in the astroglial lineage are neural stem cells. Cell Tissue Res 331:179-191.

John GR, Lee SC, Song X, Rivieccio M, Brosnan CF. 2005. IL-1-regulated responses in astrocytes: Relevance to injury and recovery. Glia 49:161-176.
Juopperi TA, Kim WR, Chiang CH, Yu H, Margolis RL, Ross CA, Ming GL, Song H. 2012. Astrocytes generated from patient induced pluripotent stem cells recapitulate features of Huntington's disease patient cells. Mol Brain 5:17.

Kacem K, Lacombe P, Seylaz J, Bonvento G. 1998. Structural organization of the perivascular astrocyte endfeet and their relationship with the endothelial glucose transporter: A confocal microscopy study. Glia 23:1-10.

Krencik R, Weick JP, Liu Y, Zhang ZJ, Zhang SC. 2011. Specification of transplantable astroglial subtypes from human pluripotent stem cells. Nat Biotechnol 29:528-534.

Kriegstein A, Alvarez-Buylla A. 2009. The glial nature of embryonic and adult neural stem cells. Annu Rev Neurosci 32:149-184.

Krug AK, Kolde R, Gaspar JA, Rempel E, Balmer NV, Meganathan K, Vojnits K, Baquie M, Waldmann T, Ensenat-Waser R, Jagtap S, Evans RM, Julien $S$, Peterson H, Zagoura D, Kadereit S, Gerhard D, Sotiriadou I, Heke M, Natarajan K, Henry M, Winkler J, Marchan R, Stoppini L, Bosgra S, Westerhout J, Verwei M, Vilo J, Kortenkamp A, Hescheler J, Hothorn L, Bremer S, van Thriel C, Krause KH, Hengstler JG, Rahnenfuhrer J, Leist M, Sachinidis A. 2013. Human embryonic stem cell-derived test systems for developmental neurotoxicity: A transcriptomics approach. Arch Toxicol 87: 123-143.

Kuegler PB, Baumann BA, Zimmer B, Keller S, Marx A, Kadereit S, Leist M. 2012. GFAP-independent inflammatory competence and trophic functions of astrocytes generated from murine embryonic stem cells. Glia 60:218-228.

Kuegler PB, Zimmer B, Waldmann T, Baudis B, Ilmjarv S, Hescheler J, Gaughwin P, Brundin P, Mundy W, Bal-Price AK, Schrattenholz A, Krause KH, van Thriel C, Rao MS, Kadereit S, Leist M. 2010. Markers of murine embryonic and neural stem cells, neurons and astrocytes: Reference points for developmental neurotoxicity testing. Altex 27:17-42.

Levitt P, Rakic P. 1980. Immunoperoxidase localization of glial fibrillary acidic protein in radial glial cells and astrocytes of the developing rhesus monkey brain. J Comp Neurol 193:815-840.

Lioy DT, Garg SK, Monaghan CE, Raber J, Foust KD, Kaspar BK, Hirrlinger PG, Kirchhoff F, Bissonnette JM, Ballas N, Mandel G. 2011. A role for glia in the progression of Rett's syndrome. Nature 475:497-500.

Liu X, Bolteus AJ, Balkin DM, Henschel O, Bordey A. 2006. GFAP-expressing cells in the postnatal subventricular zone display a unique glial phenotype intermediate between radial glia and astrocytes. Glia 54:394-410.

Lovatt D, Sonnewald U, Waagepetersen HS, Schousboe A, He W, Lin JH, Han X, Takano T, Wang S, Sim FJ, Goldman SA, Nedergaard M. 2007. The transcriptome and metabolic gene signature of protoplasmic astrocytes in the adult murine cortex. J Neurosci 27:12255-12266.

Magistretti PJ, Pellerin L, Rothman DL, Shulman RG. 1999. Energy on demand. Science 283:496-497.

Martynoga B, Mateo JL, Zhou B, Andersen J, Achimastou A, Urban N, van den Berg D, Georgopoulou D, Hadjur S, Wittbrodt J, Ettwiller L, Piper M, Gronostajski RM, Guillemot F. 2013. Epigenomic enhancer annotation reveals a key role for NFIX in neural stem cell quiescence. Genes Dev 27:1769-1786.

McFarlane HG, Kusek GK, Yang M, Phoenix JL, Bolivar VJ, Crawley JN. 2008. Autism-like behavioral phenotypes in BTBR T+tf/J mice. Genes Brain Behav 7:152-163

McKenna MC, Dienel GA, Sonnewald U, Waagepetersen HS, Schousboe A. 2012. Energy metabolism of the brain. In: Siegel G, Albers W, Brady S, Price D, editors. Basic neurochemistry. London: Elsevier. pp 201-226.

Mira H, Andreu Z, Suh H, Lie DC, Jessberger S, Consiglio A, San Emeterio J, Hortiguela R, Marques-Torrejon MA, Nakashima K, Colak D, Gotz M, Farinas I, Gage FH. 2010. Signaling through BMPR-IA regulates quiescence and long-term activity of neural stem cells in the adult hippocampus. Cell Stem Cell 7:78-89.

Monzon-Mayor M, Yanes C, Tholey G, De Barry J, Gombos G. 1990. Immunohistochemical localization of glutamine synthetase in mesencephalon and telencephalon of the lizard Gallotia galloti during ontogeny. Glia 3:81-97.

Parpura V, Heneka MT, Montana V, Oliet SH, Schousboe A, Haydon PG, Stout RFJ, Spray DC, Reichenbach A, Pannicke T, Pekny M, Pekna M, Zorec R, Verkhratsky A. 2012. Glial cells in (patho)physiology. J Neurochem 121:4-27. 
Pekny M, Leveen P, Pekna M, Eliasson C, Berthold CH, Westermark B, Betsholtz C. 1995. Mice lacking glial fibrillary acidic protein display astrocytes devoid of intermediate filaments but develop and reproduce normally. Embo J 14:1590 1598

Perea G, Navarrete M, Araque A. 2009. Tripartite synapses: Astrocytes process and control synaptic information. Trends Neurosci 32:421-431.

Robel S, Berninger B, Gotz M. 2011. The stem cell potential of glia: Lessons from reactive gliosis. Nat Rev Neurosci 12:88-104.

Roybon L, Lamas NJ, Garcia-Diaz A, Yang EJ, Sattler R, Jackson-Lewis V, Kim YA, Kachel CA, Rothstein JD, Przedborski S, Wichterle H, Henderson CE. 2013. Human stem cell-derived spinal cord astrocytes with defined mature or reactive phenotypes. Cell Rep 4:1035-1048.

Saura J. 2007. Microglial cells in astroglial cultures: A cautionary note. J Neuroinflammation 4:26.

Schildknecht S, Karreman C, Poltl D, Efremova L, Kullmann C, Gutbier S, Krug A, Scholz D, Gerding HR, Leist M. 2013. Generation of geneticallymodified human differentiated cells for toxicological tests and the study of neurodegenerative diseases. Altex 30:427-444.

Schildknecht S, Pape R, Meiser J, Karreman C, Strittmatter T, Odermatt M, Cirri E, Friemel A, Ringwald M, Pasquarelli N, Ferger B, Brunner T, Marx A, Moller HM, Hiller K, Leist M. 2015. Preferential extracellular generation of the active parkinsonian toxin $\mathrm{MPP}(+)$ by transporter-independent export of the intermediate MPDP(.). Antioxid Redox Signal 23:1001-1016.

Schneider L. 2014. Survival of neural stem cells undergoing DNA damageinduced astrocytic differentiation in self-renewal-promoting conditions in vitro. PLoS One 9:e87228.

Schneider L, d'Adda di Fagagna F. 2012. Neural stem cells exposed to BrdU lose their global DNA methylation and undergo astrocytic differentiation. Nucleic Acids Res 40:5332-5342.

Scholz D, Poltl D, Genewsky A, Weng M, Waldmann T, Schildknecht S, Leist M. 2011. Rapid, complete and large-scale generation of post-mitotic neurons from the human LUHMES cell line. J Neurochem 119:957-971.

Schousboe A, Bak LK, Waagepetersen HS. 2013. Astrocytic control of biosynthesis and turnover of the neurotransmitters glutamate and GABA. Front Endocrinol (Lausanne) 4:102.

Sergent-Tanguy S, Michel DC, Neveu I, Naveilhan P. 2006. Long-lasting coexpression of nestin and glial fibrillary acidic protein in primary cultures of astroglial cells with a major participation of nestin(+)/GFAP(-) cells in cell proliferation. J Neurosci Res 83:1515-1524.

Seri B, Garcia-Verdugo JM, McEwen BS, Alvarez-Buylla A. 2001. Astrocytes give rise to new neurons in the adult mammalian hippocampus. J Neurosci $21: 7153-7160$

Shaltouki A, Peng J, Liu Q, Rao MS, Zeng X. 2013. Efficient generation of astrocytes from human pluripotent stem cells in defined conditions. Stem Cells 31:941-952.

Shank RP, Bennett GS, Freytag SO, Campbell GL. 1985. Pyruvate carboxylase: An astrocyte-specific enzyme implicated in the replenishment of amino acid neurotransmitter pools. Brain Res 329:364-367.

Sirko S, Behrendt G, Johansson PA, Tripathi P, Costa M, Bek S, Heinrich C, Tiedt S, Colak D, Dichgans M, Fischer IR, Plesnila N, Staufenbiel M, Haass C, Snapyan M, Saghatelyan A, Tsai LH, Fischer A, Grobe K, Dimou L, Gotz M. 2013. Reactive glia in the injured brain acquire stem cell properties in response to sonic hedgehog [corrected]. Cell Stem Cell 12:426-439.

Smyth GK. 2004. Linear models and empirical bayes methods for assessing differential expression in microarray experiments. Stat Appl Genet Mol Biol 3:1-25.

Sparmann A, Xie Y, Verhoeven E, Vermeulen M, Lancini C, Gargiulo G, Hulsman D, Mann M, Knoblich JA, van Lohuizen M. 2013. The chromodo- main helicase Chd4 is required for Polycomb-mediated inhibition of astroglial differentiation. EMBO J 32:1598-1612.

Stahlberg A, Andersson D, Aurelius J, Faiz M, Pekna M, Kubista M, Pekny M. 2011. Defining cell populations with single-cell gene expression profiling: Correlations and identification of astrocyte subpopulations. Nucleic Acids Res 39:e24.

Steindler DA, Laywell ED. 2003. Astrocytes as stem cells: Nomenclature, phenotype, and translation. Glia 43:62-69.

Su Z, Niu W, Liu ML, Zou Y, Zhang CL. 2014. In vivo conversion of astrocytes to neurons in the injured adult spinal cord. Nat Commun 5:3338.

Suarez I, Bodega G, Arilla E, Fernandez B. 1997. Region-selective glutamine synthetase expression in the rat central nervous system following portocaval anastomosis. Neuropathol Appl Neurobiol 23:254-261.

Sun Y, Pollard S, Conti L, Toselli M, Biella G, Parkin G, Willatt L, Falk A, Cattaneo E, Smith A. 2008. Long-term tripotent differentiation capacity of human neural stem (NS) cells in adherent culture. Mol Cell Neurosci 38:245-258.

Teslaa T, Teitell MA. 2015. Pluripotent stem cell energy metabolism: An update. Embo J 34:138-153.

Ullensvang K, Lehre KP, Storm-Mathisen J, Danbolt NC. 1997. Differential developmental expression of the two rat brain glutamate transporter proteins GLAST and GLT. Eur J Neurosci 9:1646-1655.

Volterra A, Meldolesi J. 2005. Astrocytes, from brain glue to communication elements: The revolution continues. Nat Rev Neurosci 6:626-640.

Waagepetersen HS, Bakken IJ, Larsson OM, Sonnewald U, Schousboe A. 1998. Comparison of lactate and glucose metabolism in cultured neocortical neurons and astrocytes using 13C-NMR spectroscopy. Dev Neurosci 20:310320

Waagepetersen HS, Sonnewald U, Schousboe A. 2009. Energy and amino acid neurotransmitter metabolism in astrocytes In: Parpura V, Haydon P, editors. Astrocytes in (patho)physiology of the nervous system. Boston: Springer. pp 177-200.

Walls AB, Bak LK, Sonnewald U, Schousboe A, Waagepetersen HS. 2014. Metabolic mapping of astrocytes and neurons in culture using stable isotopes and gas chromatography-mass spectrometry (GC-MS). In: Hirlinger J, Waagepetersen HS, editors. Brain energy metabolism. New York: Springer. pp 73-106.

Walz W, Lang MK. 1998. Immunocytochemical evidence for a distinct GFAPnegative subpopulation of astrocytes in the adult rat hippocampus. Neurosci Lett 257:127-130.

Wernig M, Meissner A, Foreman R, Brambrink T, Ku M, Hochedlinger K, Bernstein BE, Jaenisch R. 2007. In vitro reprogramming of fibroblasts into a pluripotent ES-cell-like state. Nature 448:318-324.

Westergaard N, Sonnewald U, Unsgard G, Peng L, Hertz L, Schousboe A. 1994. Uptake, release, and metabolism of citrate in neurons and astrocytes in primary cultures. J Neurochem 62:1727-1733.

Wu Z, Irizarry RA, Gentleman R, Martinez-Murillo F, Spencer F. 2004. A model-based background adjustment for oligonucleotide expression arrays. J Amer Statist Assoc 99:909-917.

Zhou Y, Danbolt NC. 2013. GABA and glutamate transporters in brain. Front Endocrinol (Lausanne) 4:165

Zimmer B, Kuegler PB, Baudis B, Genewsky A, Tanavde V, Koh W, Tan B, Waldmann T, Kadereit S, Leist M. 2011a. Coordinated waves of gene expression during neuronal differentiation of embryonic stem cells as basis for novel approaches to developmental neurotoxicity testing. Cell Death Differ 18:383395

Zimmer B, Schildknecht S, Kuegler PB, Tanavde V, Kadereit S, Leist M. $2011 \mathrm{~b}$. Sensitivity of dopaminergic neuron differentiation from stem cells to chronic low-dose methylmercury exposure. Toxicol Sci 121:357-367. 